OPEN ACCESS

Edited by:

Sandra Tuyaerts,

University Hospital Brussels,

Belgium

Reviewed by:

Yong Liu,

Nanjing Drum Tower Hospital,

China

William J. Magner,

University at Buffalo,

United States

*Correspondence:

Guixiang Liao

liaoguixiang@163.com

Specialty section:

This article was submitted to

Cancer Immunity and

Immunotherapy,

a section of the journal

Frontiers in Immunology

Received: 26 July 2020 Accepted: 16 October 2020

Published: 19 November 2020

Citation:

Khan M, Zhao Z, Arooj S, Fu Y and Liao G (2020) Soluble

$P D-1$ : Predictive, Prognostic, and Therapeutic Value

for Cancer Immunotherapy.

Front. Immunol. 11:587460. doi: 10.3389/fimmu.2020.587460

\section{Soluble PD-1: Predictive, Prognostic, and Therapeutic Value for Cancer Immunotherapy}

\author{
Muhammad Khan ${ }^{1,2}$, Zhihong Zhao ${ }^{3}$, Sumbal Arooj ${ }^{1,4}$, Yuxiang Fu ${ }^{1}$ and Guixiang Liao ${ }^{1 *}$ \\ ${ }^{1}$ Department of Radiation Oncology, Shenzhen People's Hospital, The First Affiliated Hospital of Southern University of \\ Science and Technology, Shenzhen, China, ${ }^{2}$ Department of Oncology, First Affiliated Hospital of Anhui Medical University, \\ Hefei, China, ${ }^{3}$ Department of Nephrology, Shenzhen People's Hospital, Second Clinical Medicine Centre, Jinan University, \\ Shenzhen, China, ${ }^{4}$ Department of Biochemistry, University of Sialkot, Sialkot, Pakistan
}

Programmed death protein 1 (PD-1) interaction with PD-L1 deliver immunosuppressive environment for tumor growth, and its blockade with directed monoclonal antibodies (antiPD-1/anti-PD-L1) has shown remarkable clinical outcome. Lately, their soluble counterparts, SPD-1 and SPD-L1, have been detected in plasma, and elevated levels have been associated with advanced disease, clinical stages, and worst prognosis for cancer patients. Elevated plasma levels of SPD-L1 have been correlated with worst prognosis in several studies and has displayed a persistent outlook. On the other hand, sPD-1 levels have been inconsistent in their predictive and prognostic ability. Pretherapeutic higher SPD-1 plasma levels have shown to predict advanced disease state and to a lesser extent worst prognosis. Any increase in SPD-1 plasma level post therapeutically have been correlated with improved survival for various cancers. In vitro and in vivo studies have shown SPD-1 ability to bind PD-L1 and PD-L2 and block PD-1/PD-L1 interaction. Local delivery of SPD-1 in cancer tumor microenvironment through local gene therapy have demonstrated an increase in tumor specific CD8+ T cell immunity and tumor growth reduction. It had also exhibited enhancement of $\mathrm{T}$ cell immunity induced by vaccination and other gene therapeutic agents. Furthermore, it may also lessen the inhibitory effect of circulating SPD-L1 and enhance the effects of mAb-based immunotherapy. In this review, we highlight various aspects of SPD-1 role in cancer prediction, prognosis, and anticancer immunity, as well as, its therapeutic value for local gene therapy or systemic immunotherapy in blocking the PD-1 and PD-L1 checkpoint interactions.

\section{Keywords: soluble programmed cell death protein 1, local gene therapy, cancer vaccination, prediction, prognosis, immune checkpoint blockade}

\section{INTRODUCTION}

Adaptive immune system comprising T cells (CD 4+ and CD 8+ T cells) and B cells is capable of destroying and eliminating any foreign harmful invader while sparing normal healthy cells through self-tolerance (1). Antigens are presented to $\mathrm{T}$ cells by antigen presenting cells (APCs) for elimination through $\mathrm{T}$ cells activation, and induction of its effector functions $(2,3)$. T cell receptor (TCR) binding to MHC-peptide complex presented by APCs, and the costimulatory 
receptor CD28 to its ligands CD80/86 present on APCs results in $\mathrm{T}$ cell stimulation (2-4). In order to avoid overactivation, negative regulators such as CTLA-4 is induced on the T cells (5). CTLA-4 competes for same ligands as CD28 and cause T cell inhibition (6). Programmed cell death protein (PD-1) is also induced after $\mathrm{T}$ cell is activated for which ligands on cancer cells and APCs are up-regulated $(7,8)$. PD-1 and PD-L1 interaction results in inhibition of its effector function such as cytotoxicity and cytokine release, restricts $\mathrm{T}$ cell proliferation and survival, and induces apoptotic death of tumor-specific $\mathrm{T}$ cells (9). Furthermore, differentiation of CD4+ $\mathrm{T}$ cells into Fox3+ regulatory $\mathrm{T}$ cells is also promoted (10). As a result, these coinhibitory pathways have been proven to be the key mechanism for tumor immune evasion as high and sustained PD-1 \& PD-L1/L2 expression is often reported in cancer and chronic infections $(11,12)$. Blocking this pathway has shown improvements in $\mathrm{T}$ cells functionality and cancer patients' survival (13-15). As such, PD-1/PD-L1 interaction has become the corner stone for understanding the physiology of these inhibitory co-receptors in immune system also termed as inhibitory immune checkpoints.

PD-1 and PD-L1 broad range of expression and complex regulation is indicative of its intricate functional domain $(12,16)$. Recently, its detection in plasma of cancer patients has open a new paradigm for investigations (17-19). Even though, these soluble forms are mainly evaluated for their predictive and prognostic significance, they still retain their inhibitory functionality (18-20). In this review we will elucidate the anticancer properties of soluble $\mathrm{PD}-1$, its predictive, prognostic as well as therapeutic value. In order to fully comprehend the role of soluble PD-1, a short review of membrane-bound PD-1/PD-L1 structure, expression, regulation, and mechanism of interaction between PD-1 and PD-L1 is outlined.

\section{STRUCTURE OF PD-1}

Membrane-bound PD-1 is a type I transmembrane glycoprotein belonging to CD28 family of receptors, a subgroup of immunoglobulin superfamily $(21,22)$. PD-1 gene was first discovered in $\mathrm{T}$ cell hybridoma and hematopoietic progenitor cell line as an upregulated gene (23). PD-1, a $55 \mathrm{kDa}$ glycoprotein of 288 amino acids, is composed of $\mathrm{N}$-terminal $\mathrm{IgV}$ like domain that also contain the signal sequence, a 20 amino-acid stalk, a transmembrane domain, and a 95 amino-acid intracytoplasmic domain that contains two tyrosine-based signaling motifs (24) (Figure 1). PD-1 IgV-like domain shares about $21 \%$ to $33 \%$ sequence resemblance with other CD28 family members such as CD28, ICOS, and CTLA-4. PD-1 lacks intracellular SH2 (Src Homology 2) or SH3 binding motifs unlike CD28 and CTLA-4 (25). Its Intracellular domain contains one N-terminal sequence (VDYGEL) constituting an immunoreceptor tyrosine based inhibitory motif (ITIM) and one C terminal sequence (TEYATI) forming an immunoreceptor tyrosine-based switch motif (ITSM) (26). SHP2 recruitment by ITSM phosphorylation results in the inhibitory function associated with PD-1. PD-1 is

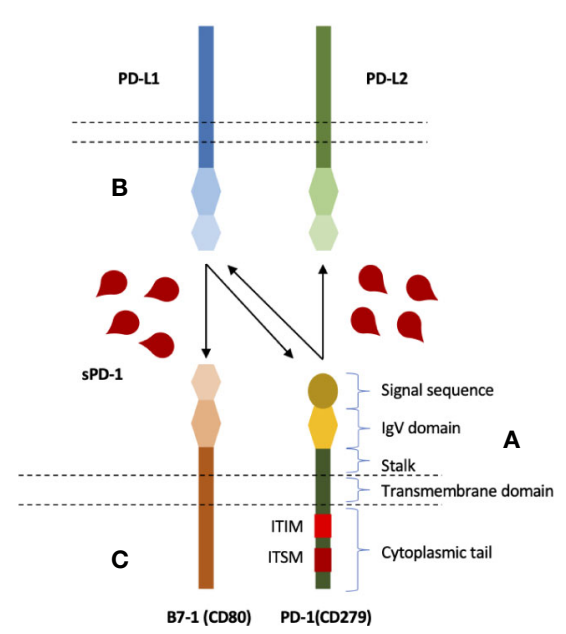

FIGURE 1 | Structure and interactions of PD-1 immune checkpoint molecule, and blocking potential of soluble PD-1. (A) PD-1 is composed of an extracellular IgV like domain carrying signal sequence, a transmembrane domain, an intracellular domain that contains two signaling motifs, ITIM and ITSM. (B) PD-1 expressed on the surface of $T$ cells (and several other cells) can bind to its ligands; PD-L1 and PD-L2. (C) PD-L1, in addition to PD-1, has also been shown to interact with B7-1 expressed on T cells. B7-1 and PD-L1 interactions can also inhibit T cells. Soluble PD-1, therefore, can potentially inhibit all three interactions.

produced as monomer as it lacks the cysteine residue that is required for homodimerization (21).

\section{PD-1/PD-L1 EXPRESSION AND UP-REGULATION}

PD-1 is up-regulated on T cells after its activation, and is also expressed on other immune cells such as B cells, NK cells, and NKT cells $(11,16,22,27)$. A small portion of myeloid cells, APCs, and innate lymphoid cells (IL2) have also shown PD-1 expression $(11,16,22,27,28)$. In mouse $\mathrm{T}$ lymphocytes, a stronger feedback for $\mathrm{T}$ cell mediated immunity was generated with synergistic actions of TCR signals and IFN- $\alpha$ in regulating the expression of PD-1 (29). IFN- $\alpha$ had also exhibited its regulation of $\mathrm{PD}-1$ in macrophages through JAK/STAT signaling pathway (30). IL-6 and IL-12 had also augmented TCR-induced PD-1 expression by activating STAT3/STAT4 (31). In addition, PD-1 expression on $\mathrm{T}$ cells can also be induced by cytokines such as IL-2, IL-7, IL-15, and IL-21 (32). Its ligands, PD-L1 and PD-L2, are mainly upregulated on APCs and various cancer cells. PD-L1 expression is diverse and several non-hematopoietic cells have also demonstrated PD-L1 expression such as vascular endothelial cells, non-parenchymal cells of the liver, pancreatic islets, placental syncytiotrophoblasts, keratinocytes and the cornea $(11,16,22,27,28)$. Regulation of PD-L1 is extensively elaborated particularly in cancer cells as it is the main tactic for immune evasion. PD-L1 regulation in cancer cells involve several extrinsic and intrinsic factors. PD-L1 
expression was increased with 9q24.1gene amplification in nodular sclerosing Hodgkin lymphoma and primary mediastinal large B-cell lymphoma (33). Elevated levels of transcriptional factors STAT3 and HIF-1 $\alpha$ were also associated with PD-L1 expression in various cancers $(34,35)$. Oncogenic aberrant signaling pathways such as EGFR, MAPK, PI3k-AKT were shown to upregulate PD-L1 in lung cancers (36-38), various cytokines have shown to mediate PD-L1 expression including IFN- $\gamma$, IFN- $\alpha$, IL-2, IL-6, IL-10, IL-12, IL-15, IL-17, IL-25, IL-27 (32, 36, 39-44). Viral infections such as EBV have also shown to drive PD-L1 expression in gastric and nasopharyngeal cancers $(45,46)$. Long non-coding RNAs and microRNAs are associated with negative regulation of $\mathrm{PD}-\mathrm{L} 1$ expression. Long non-coding RNA (lncRNA), NKX2-1, limits lung carcinoma cell migration through negatively regulating PD-L1 expression (47). Similarly, several microRNAs including miR-34a, miR-200, miR-152, miR-155, miR-513, and miR-570 negatively regulate PD-L1 expression in cancers (48-54). PD-L2 on the other hand is mainly expressed by dendritic cells, macrophages, in some mast cells. In addition, it has also been reported to express on some B cells, Th2 cells and few types of cancers $(11,16,22,27,28)$. Such diverse expression of this checkpoint suggests a broad functional domain (16). Inhibition of T cells primarily through PD-1 interaction with PD-L1 mainly involves two counterparts; antigen presenting cells, and cancer cells. PD-1/PD-L1 interaction leads to a chain of intracellular events in T cells, which ultimately culminate in $\mathrm{T}$ cell inhibition and tumor immune tolerance.

\section{MECHANISM OF T CELL INHIBITION}

Triggering of PD-1 mediated intracellular signaling upon PD-L1 ligation mainly results in the suppression of two main pathways; PI3K-Atk-mTOR, and RAS-MEK-ERK $(55,56)$ (Figure 2). Suppression of these pathways restricts cell growth, differentiation, cell cycle progression, and cell division, proliferation and cell survival. Intracytoplasmic tail of PD-1 contains ITSM motif which recruits SHP-1/2 upon phosphorylation (57). ITSM-recruited SHP-2 results in impaired phosphorylation of ZAP70 and LCK, proximal signaling molecules of TCR, with subsequent inhibition of PI3K-AKT-mTOR pathway (55). In addition, PD-1 was also shown to inhibit downstream signaling to PKC $\theta$ (55). Another mechanism by which PI3K-AKT-mTOR pathway is inhibited by PD-1 involves the phosphorylation and phosphatase activity of the PTEN (58-60). PTEN inhibits PI3K pathway while its phosphorylation by CK2 during T cell activation ensues PTEN stability and reducing PTEN lipid phosphatase activity $(58,59)$. PD-1, on the other hand, disrupts the PTEN stability and increase the phosphatase activity by inhibiting the CK2 mediated phosphorylation (60). PD-1 mediated inhibition of the PI3K pathway suppresses oxygen consumption; affecting $\mathrm{T}$ cell glycolytic and glutaminolytic activity, which are up-regulated upon $\mathrm{T}$ cell activation (61-64). It inhibits the mitochondrial and amino acid metabolism while beta-oxidation of fatty acids

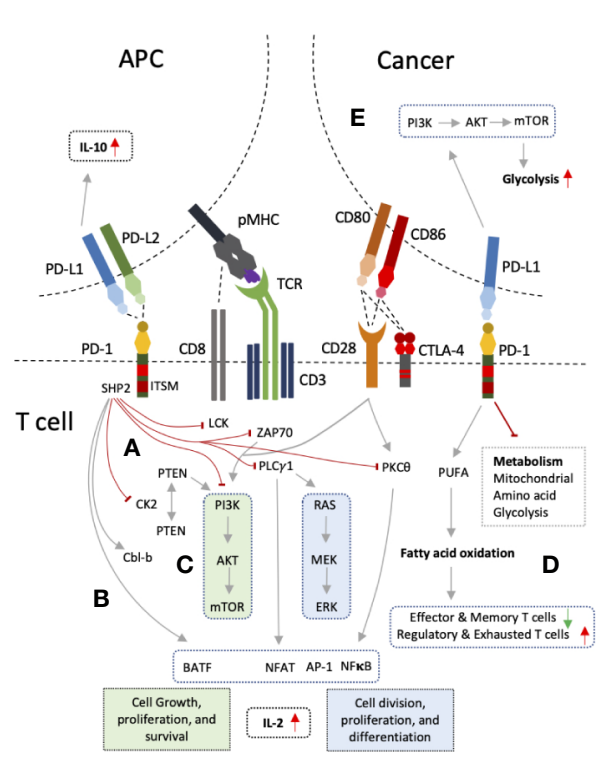

FIGURE 2 | PD-1 and PD-L1 interactions and mechanism of T cell inhibition. (A) PD-1 ligation to PD-L1 leads to recruitment of SHP2 by its intracellular signaling motif, ITSM. SHP2 exerts its inhibitory action on proximal signaling molecules of T cell receptor (TCR) such as LCK, ZAP70 resulting PI3K pathway inhibition. PI3K pathway is also inhibited through PTEN by inhibiting CK2. PLC- $\gamma 1$ and PKC $\theta$ are also inhibited results in RAS pathway inhibition, decrease production of IL-2, and reduce expression of several transcription factors such NFAT, NFkB, and AP-1. (B) PD-1 also up-regulate Cbl-b and transcription factor BATF. (C) The outcome is inhibition of two main signaling pathways PI3K-AKT-mTOR and RAS-MEK-ERK which results in decreased cell division, growth, proliferation, differentiation, and survival. (D) Inhibition of these pathways also lead in altered T cell metabolism with increased inhibition of glycolysis, mitochondrial and amino acid metabolism, and increased fatty acid oxidation. (E) Reverse signaling through PD-L1 can also occur in tumor cells and antigen presenting cells (APCs) resulting in PI3K pathway up-regulation and enhanced glycolysis in cancers, and increased IL-10 production in DCs.

is promoted (64). PD-1 ligation is also associated with polyunsaturated fatty acids accumulation which can suppress T cell immunity $(64,65)$.

The second major pathway, RAS-MEK-ERK pathway, is disrupted by PD-1 through inhibition of PLC- $\gamma 1$ (56). $\mathrm{Ca}^{2+}$ and DAG (diacylglycerol), downstream of PLC- $\gamma 1$, activate the RasGRP1 resulting in RAS-MEK-ERK pathway activation (66). Calcium influx also results in dephosphorylation of NFAT and its translocation to nucleus. Cooperation of NFAT with AP-1, one of the three transcription factors (NFAT, NFKB, AP-1) activated after CD28 interaction with its ligands (CD80/86), is required for IL-2 gene transcription and mRNA stability (67). $\mathrm{PD}-1$ ligation has also been reported to up-regulate $\mathrm{Cbl}-\mathrm{b}$, which is associated with PI3K inhibition either directly or through suppression of PTEN inactivation (68-70). Besides, Cbl-b also reduces PLC- $\gamma 1$ activation in anergic $\mathrm{T}$ cells $(71,72)$. On the other hand, PD-1 increases expression of BATF transcription factor, and p38 MAP kinase pathway is left unaffected affecting cell differentiation, apoptosis and autophagy $(56,73)$. PD-L1 has no such signaling motifs in its cytoplasmic; hence, incapable of 
carrying out any signaling $(74,75)$. However, it was shown to function as inhibitory receptor preventing apoptotic death of cancer cells which necessitated the intracellular domain of PD-L1 (74). Furthermore, association of PD-L1 expression on cancer cells with PI3K-AKT-mTOR signaling pathway and enhancement of glycolytic metabolism indicates PD-L1 may also mediate reverse signaling (75). Reverse signaling through PD-L1 expression has also been shown (76). Blocking PD-L1 on DCs with SPD-1 was able to inhibit DCs and increase in IL-10 production (76). Hence, PD-1 pathway essentially downmodulate TCR and CD28 signaling, decreased induction of downstream transcription factors, and decrease cytokine production resulting in decreased $\mathrm{T}$ cell proliferation and survival.

\section{SOLUBLE PRODUCTION}

Soluble forms of many immune regulatory molecules, both costimulatory and co-inhibitory molecules, are detected in plasma of cancer patients including sCTLA-4, sHLA-G, sCD80, sB7-H3, sCD86, sBTLA, sLAG-3, sCD27, s4-1BB, and sCD40 (19, 77, 78). These soluble forms are either produced by shedding off the membrane form or through alternate splice variants (79). Four splice variants of PD-1 have been discovered while sPD-L1 is mainly thought to be produced by proteolytic cleavage of membrane-bound PD-L1 (80). Full length PD-1 (flPD-1) is composed of five exons (exons 1-2), while its fours splice variants arises with the deletion of middle exons 2,3 , and 4 (Figure 3). Splice variant PD-1 $\triangle \mathrm{x} 2$ is generated with deletion of exon 2 corresponding to the extracellular IgV domain; hence, it is

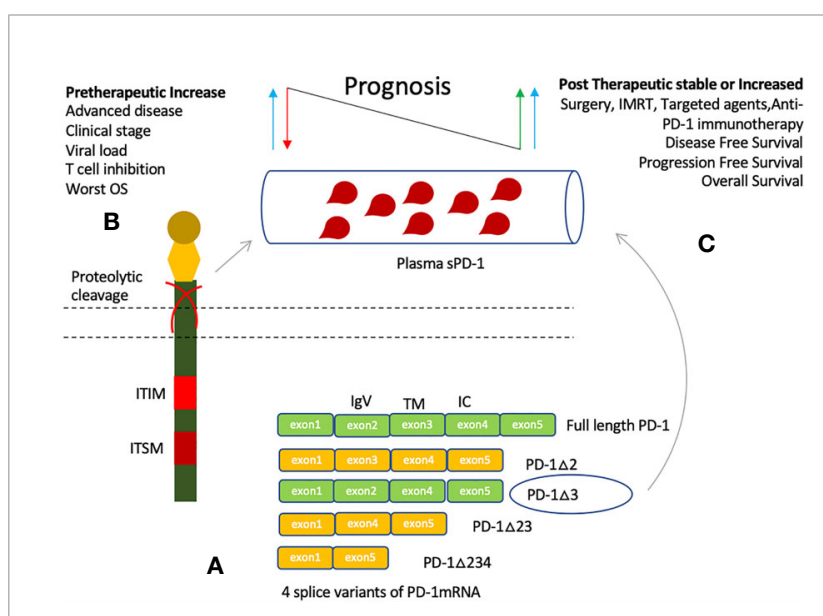

FIGURE 3 | Production of soluble PD-1 and clinical significance of its elevated plasma levels. (A) Soluble PD-1 may be produced by proteolytic cleavage or through alternative splicing. Four splice variants are identified, only PD-1 $\triangle 3$ may represent the soluble PD-1 as it can bind its ligands. Other splice variants lack exon 2 and hence no extracellular lgV like domain. (B) Elevated plasma levels are detected in several cancers, and associated with viral load, cancer risk, clinical stages of cancer, and worst prognosis. (C) An increase in SPD-1 levels after induction of therapy have been associated with improved Disease-free survival (DFS), Progression-free survival (PFS), and Overall survival (OS). unable to bind its ligands. Similarly, PD- $\triangle \triangle \mathrm{x} 2 / 3$ and $\mathrm{PD}$ $1 \triangle \mathrm{x} 2 / 3 / 4$, are also unable to bind its ligands as they have no exon 2. PD-1 $\triangle$ ex2,3,4, in addition to exon 2 and 3, also lacks exon 4 that encodes the intracellular domain, and contains a premature stop codon in exon 5. Only, PD-1 $\triangle \mathrm{x} 3$ can encode soluble form of PD-1 as it retains the extracellular domain, and only lacks exon 3 corresponding to the transmembrane region of PD-1. Increased level of each PD-1 transcript was seen upon activation of human PBMCs with anti-CD3 plus anti-CD28 monoclonal antibodies. Upon activation, a parallel increase in expression of flPD-1 and PD- $1 \triangle \mathrm{x} 3$ was observed indicating an important interplay between the soluble and membrane form of PD-1 in maintenance of peripheral self-tolerance and prevention of autoimmunity (80). Reduction of HCC decreased the sPD-1 levels suggesting primary tumor site and tumor-specific $\mathrm{T}$ cells as the prime source of circulating PD-1 (81). Low sPD-1 plasma levels were associated with brisk tumor-infiltrating lymphocytes (TILs), moderate levels with non-brisk TILs, and high levels with absent TILs in primary melanoma patients indicating engaged $\mathrm{T}$ cells may produce more mPD-1 but low soluble forms and peripheral tumor specific $\mathrm{T}$ cells may constitute the main source of elevated PD-1 levels (82). Furthermore, a positive correlation was observed between the levels of sPD-1 and sPDL1 in advanced pancreatic cancer signifying a common provenience and simultaneous release $(83,84)$. In cancer patients, studies have reported parallel elevation of both soluble molecules, PD-1 and PD-L1, in plasma suggesting they may have regulatory properties in order to counter the effect of each other as in the case of membrane-bound up-regulation (8388). Patients with HCC had also observed a positive correlation in the fold-changes of sPD-1 and sPD-L1 at 2 weeks of sorafenib treatment (77). It indicates that a balance between the two molecules may exist locally or in the peripheral circulation as inhibitory signals are mainly required for maintaining balance in the immune system: a state of immune homeostasis (16). Hence, increasing either may impede the function of the other. An increase in sPD-1 may suggest further inhibition of sPD-L1/ mPD-L1 thereby avoiding the T cell from inhibition. Similarly, an increase in SPD-L1 may further strengthen T cell inhibition, strengthening cancer immune evasion, and resulting in poor outcome.

\section{PREDICTIVE AND PROGNOSTIC SIGNIFICANCE}

Higher SPD-1 levels are predictive of active and advanced disease as well as worst prognosis (81-92). Soluble PD-1 levels association with systemic inflammation markers (CRP), active disease, hepatitis B viral load, HCC (Hepatocellular carcinoma) risk, and worst prognostic factors in DLBCL (Diffuse large B-cell lymphoma) is indicative of its predictive value $(83,84,89,90)$. However, its association with poor prognosis is not fully established. Pretherapeutic increase has been related to worst prognosis in various cancers $(81,84)$. On the other hand, studies have shown stable or increase in SPD-1 level after induction of cancer therapy was associated with improved outcome such as 
surgery, IMRT (Intensity-modulated radiotherapy), and EGFR TKIs (Epidermal growth factor receptor tyrosine kinase inhibitors) $(86,88,91)$.

\section{Pretherapeutic Increase}

Chronic inflammation, autoimmune disease and cancers are reported to have higher tissue expression and plasma levels of coinhibitory molecules, PD-1 and PD-L1 (81-97). As such, elevated levels of sPD-1 have been detected in several cancers such as NSCLC (Non-small cell lung carcinoma), DLBCL, CLL (Chronic lymphocytic leukemia), NPC (Nasopharyngeal carcinoma), HCC, pancreatic adenocarcinoma, advanced rectal cancer, and metastatic melanoma (81-92) (Figure 3). Pretherapeutic higher plasma levels have been associated with disease severity, clinicopathological features, and viral load as well as prognosis $(81,83,84,89-91)$. sPD-1 was detected in $21 \%$ of NSCLC patients prior to erlotinib treatment, and in $37 \%$ at disease progression (91). Advanced pancreatic cancer patients with elevated levels of systemic inflammation marker, CRP, had a trend towards higher mean sPD-1 levels; yet, no association for higher sPD-1 levels with worst survival was observed (83). However, in a separate study of 32 pancreatic adenocarcinoma patients, high sPD-1 levels were associated with worst survival (84). HBV (Hepatitis B virus) patients had higher sPD-1 plasma levels in comparison to HBV resolvers and healthy controls (81). Higher sPD-1 levels were indicative of $\mathrm{HBV}$ viral activity and HCC risk (89). HBV-related HCC had higher sPD-1 levels as compared to other HBV clinical diseases, and was associated with poor survival (81). In retrospectively analyzed 120 HCC patients treated with radical resection, higher $\mathrm{SPD}-1$ level was associated with improved disease-free survival (DFS) and overall survival (86). In patients with DLBCL, elevated pretherapeutic sPD-1 levels were associated with worst prognostic indicators such as age $(\geq 60)$, disseminated clinical stage, performance status (ECOG $\geq 2$ ), elevated levels of plasma $\mathrm{LDH}$, and presence of $\geq 1$ extranodal site (90). sPD-1 levels have also been revealed to be higher in certain genotype or phenotype of disease. HBV genotype $\mathrm{C}$, and non-GCB phenotype of DLBCL cancer patients had higher sPD-1 levels $(89,90)$. These outcomes suggest that $\mathrm{sPD}-1$ levels are detected in patients with chronic infections and cancer, and may increase at disease progression. However, depending on the treatment undertaken, it may or may predict survival outcome.

\section{Post-Therapeutic Increase}

On the other hand, post therapy sPD-1 levels' stability or increase have demonstrated a distinct behavior. No significant increase in sPD-1 levels were observed after induction of neoadjuvant chemoradiotherapy in advanced rectal cancer patients, and no association with survival was established (92). NSCLC patients treated with EGFR TKIs, however, were revealed to have increased the $\mathrm{SPD}-1$ levels which was associated with improved progression free survival and overall survival (91). Recently, studies have reported enhancement of immunogenicity and clinical response after anti-EGFR mAb cetuximab or nimotuzumab through STAT1-induced HLA class I upregulation $(98,99)$. As HLA-I upregulation is associated with tumor-specific CD8+ mediated immune response, these cells may also lead into sPD-1 secretion after anti-EGFR treatment. Increase in SPD-1 was associated with a decrease plasma EBV-DNA level and improved survival in patients with nasopharyngeal carcinoma patients after Definitive Intensity-Modulated Radiotherapy (IMRT) (88) (Figure 3). One may speculate that the increase in sPD-1 levels may indicate radiotherapy induced immunity as radiotherapy is associated with increase in antigen presentation resulting in increased amount of tumor-specific $\mathrm{T}$ lymphocytes leading to an increase in soluble PD-1 production $(100,101)$. PFS and OS was also improved for NSCLC patients with a stable or increase in sPD-1 after undertaking two cycles anti-PD-1 mAb therapy (nivolumab) (87). The underlying mechanism for sPD-1 increase after certain treatments (radiotherapy, anti-EGFR therapy, and anti-PD-1 immunotherapy) has not been investigated $(87,88$, 91). It may indicate re-activation of tumor-specific cytotoxic $\mathrm{T}$ lymphocytes as these cells make up the primary source of sPD-1 in circulation $(81,83,84)$. Re-activation can result partly from improving antigen presentation by APCs, upregulation of HLA-I on tumor cells, and alleviating T cells' inhibition after treatments such as radiotherapy, anti-EGFR mAbs/molecular agents, and anti-PD-1 immunotherapy (87, 88, 91, 98, 99). Furthermore, increase in sPD-1 levels after treatment was associated with improved outcomes in terms of decreasing plasma EBV-DNA level, and improving PFS and OS $(87,88,91)$. It indicates increased SPD-1 level represents immunogenicity and that sPD-1 is biologically active. As our understanding broadens about the underlying mechanism of efficacy of such treatments, we may better analyze the mechanism of sPD-1 increase and its role in improving the outcome of cancer patients.

\section{ANTI-CANCER ACTIVITY}

Soluble PD-1, just like membrane-bound PD-1, is biologically active and can inhibit mPD-1/PD-L1 and mPD-1/PD-L2 interactions (102-105). sPD-1 blockade has shown to regulate $\mathrm{T}$ cell functions through $\mathrm{PD}-\mathrm{L} 1 / 2$ blockade in various autoimmune diseases, chronic infections, and antitumor immunity (102-107). Several animal studies have evaluated the anti-cancer effects of sPD-1 though local gene transfer using eukaryotic expression plasmid and other viral vectors (102-105, 107) (Figure 4). Increase in activation and cytotoxicity of T cells, and reduction in tumor growth was observed through in vitro and in vivo blockade of PD-L1 by sPD-1 transferred via eukaryotic expression plasmid (102-105). In vitro blockade of PD-Ls expressed on H22 cells showed enhanced tumor cell lysis by HSP70-peptide complex-stimulated spleen cells (103). H22 cells and spleen cells expressing both PD-L1 and PD-L2 were also shown to be inhibited by secreting $\mathrm{SPD}-1$ plasmid transfected cells (103). In animal model of BALB/c mice inoculated with $\mathrm{H} 22$ hepatoma, not only rate of tumorigenesis was slowed but also lower number of mice had displayed tumorigenesis injected with pPD-1A (103-105). Moreover, inhibitory effect of sPD-1 on tumor was similar to that of mice injected with anti-PD-L1 $\mathrm{mAb}$ (103). Similarly, reconstructed adeno-associated virus 


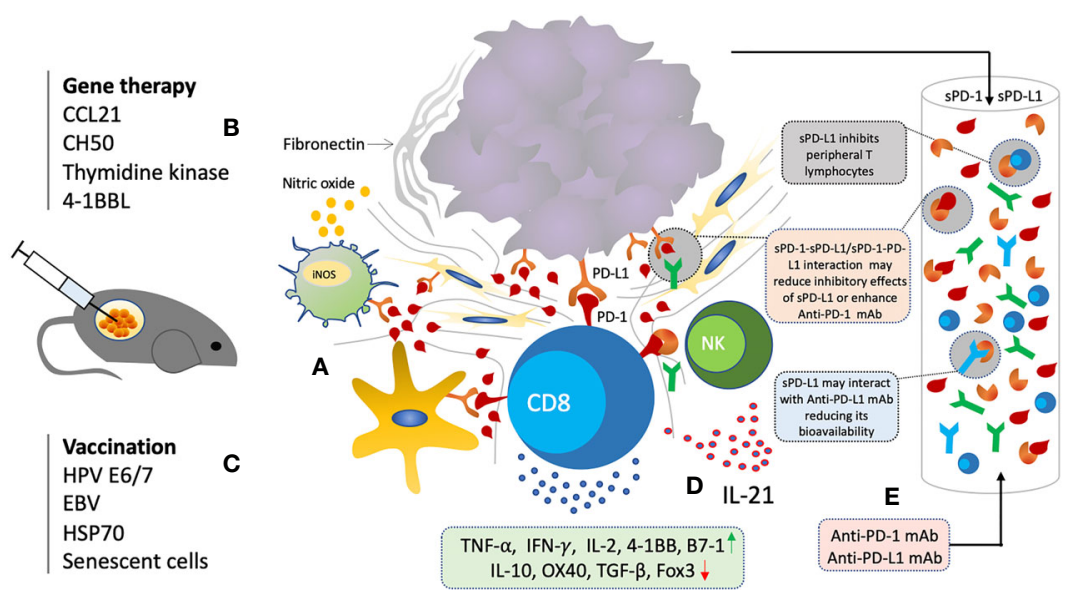

FIGURE 4 | Soluble PD-1 based therapeutic strategy. (A) Local gene delivery of SPD-1 induce anti-cancer immunity and reduction in tumor growth through interruption of PD-1/PD-L1 interactions in TME. (B) Combination of SPD-1 with other gene therapeutic agents targeting cancer cell survival, chemotaxis, and costimulatory molecules have shown synergistic activity (C) Combination of sPD-1 also enhance vaccine induced immunity and overcome vaccine resistance. (D) Combination of SPD-1 also enhance IL-21 induced immunity through increase infiltration and cytotoxicity of CTLs and NK cells (E) Elevated levels of sPD-1 and SPD-L1 may have regulatory functions and interfere with anti-PD-1/PD-L1 mAb based immunotherapy.

plasmid encoding sPD-1 was also shown to induce anti-tumor immunity (107). sPD-1 was able to regress tumor and prolong survival of tumor bearing mice (107). sPD-1 treated mice exhibited tumor-specific cytotoxic T cells infiltration (107). IL-10 pretreated DCs with up-regulated PD-L1 and decreased co-stimulatory ability for lymphocytes activation showed enhanced lymphocytic activation after co-culturing with pPD-1A-transfected BHK cells (103). Enhanced cytotoxicity was observed even when the $\mathrm{H} 22$ cells were pretreated with sPD-1 indicating that sPD-1 inhibiting the PD-Ls present on DCs resulting in T cell activation (103-105). Splenocytes were revealed to have significantly increased mRNA expression of IFN- $\gamma$ with moderate increase in TNF- $\alpha, 4-1 \mathrm{BB}$, and B7-1, while that of OX40 and IL-10 were downregulated (103). Such panel is indicative of CD8+ $\mathrm{T}$ cells activation probably through 4-1BB/4-1BBL and B7-1. Down-regulation of OX40 and IL-10 suggests that the CD4+ $\mathrm{T}$ cells may not play any critical role in sPD-1 dependent antitumor immunity improvement. Membranebound PD-1 blockade has also shown a similar augmentation of Th1/Th17 response with enhanced production of IFN- $\gamma$, IL-2, TNF$\alpha$, IL- 6 , and IL-17A, and reduction of Th2 cytokines IL-15 and IL-13 (108). Likewise, soluble PD-1 was also shown to aggravate the progression of collagen-induced arthritis through Th1 and Th17 pathways (109). Overall, sPD-1 is shown to increase anti-tumor immunity through in vitro and in vivo blockade of PD-L1 and PD-L2 present on DCs and cancer cells with an increase in activation, cytotoxicity, cytokine production, and infiltration of CD8+ T cells.

Reverse signaling through sPD-1 interactions with PD-L1 and PD-L2 expressed on DCs has also been demonstrated resulting in decreased OVA-specific CD4+ T cells and inefficient DC maturation at low doses of antigen (76). However, increased $\mathrm{T}$ cell proliferation was shown at higher antigen concentration indicating sPD-1 effects may differ depending on the strength of TCR signaling and degree of DC maturation. Such reduced DC maturation and increased apoptosis was also revealed in HIV infected individuals with an in vitro PD-L1 engagement of sPD-1 protein on myeloid DCs (110). On the other hand, in vivo codelivery of sPD-1 DNA with DNA vaccine demonstrated enhanced DC maturation probably indirectly through blockade of signals delivered by PD-1 on T cells (111). Several other reports have also shown such $\mathrm{T}$ cell activation mediated $\mathrm{DC}$ maturation $(112,113)$. In addition, PD-L1 has also been reported to interact with B7-1 and inhibit T cell activation and cytokine production (114). Hence, sPD-1 can also inhibit PD-L1:B7-1 interactions in addition to its ligands, PD-L1 and PD-L2.

Soluble PD-1 had also shown enhancement of the anti-tumor effects induced by other gene-therapeutic agents such as secondary lymphoid tissue chemokine (SLC, CCL21), Herpes Simplex Type 1 Thymidine Kinase (TK) (HSVtk), a recombinant fibronectin (CH50), and 4-1BB ligand gene, mainly through strengthening CD8+ T cell responses resulting in tumor growth reduction (104, 115-118) (Figure 4). Anti-tumor immunity induced by several vaccine agents were also improved with $\mathrm{sPD}-1$ delivery such as HSP70 vaccine, and human papilloma virus-16 E7 DNA vaccines $(111,119,120)$. Furthermore, it had also been able to enhance the T cell and NK cell immunity induced by IL-21 through blocking the PD-1/PD-L1 interaction pathway (121). Such broad scope potential of sPD-1 local gene delivery indicates its great potential for anticancer therapy.

\section{IMPLICATIONS FOR ANTI-CANCER THERAPY}

In vitro blockade of $\mathrm{PD}-\mathrm{L} 1$ and $\mathrm{PD}-\mathrm{L} 2$ has been demonstrated with sPD-1 through local gene transfer (102-105). sPD-1 through binding to $\mathrm{mPD}-\mathrm{L} 1 / \mathrm{L} 2$, its interaction with these ligands could prevent the $\mathrm{mPD}-1$ on $\mathrm{T}$ cells from binding 
thereby avoiding $\mathrm{T}$ cell inhibition. Recently, PD-L1 has also been reported to bind to $\mathrm{B} 7-1$ (CD80) resulting in $\mathrm{T}$ cell inhibition in an indirect manner by preventing CD80:CD28 interaction (114). Hence, in addition to blocking PD-1/PD-L1 and PD-1/PD-L2 interactions, sPD-1 may also interrupt PD-L1/B7-1 interaction by binding to PD-L1 (Figure 1). Furthermore, it may also block the inhibitory action of circulating SPD-L1 as it has been associated with worst survival and impediment to ICB (immune checkpoint blockade) $(17,122)$. Therefore, increasing the sPD-1 level locally or systematically may have several implications for cancer immunotherapy.

\section{Reducing Inhibitory Effects of Circulating Soluble PD-L1}

An enormous amount of clinical research has been going on in the last few years about the predictive, prognostic, and regulatory functions of circulating PD-L1 levels. Circulating PD-L1 is biologically active and has been shown to inhibit $\mathrm{T}$ cell functions in various cancers $(20,123,124)$. Higher plasma levels have been well correlated with disease status, severity and prognosis $(83-88,92,125,126)$. Elevated levels of circulating PD-L1 have also been shown to predict various treatments' efficacy such chemotherapy, radiotherapy, and immunotherapy (17, 122, 127-134). As described earlier, plasma levels of sPD-1 produced by tumor-specific T lymphocytes and sPD-L1 secreted by cancer cells have shown proportionality, suggesting a state of immune homeostasis that is favoring tumor cells (83-88). Hence, hypothetically, increasing the sPD-1 levels which can bind to these circulating PD-L1 as well as mPD-L1 may essentially lessen $\mathrm{T}$ cell inhibition (Figure 4). As such, sPD-1 delivery holds great potential as an anti-cancer strategy to alleviate $\mathrm{T}$ cell inhibition. Furthermore, sPD-1 delivery in combination with these treatments may also enhance their anticancer efficacy.

\section{Soluble PD-1 as Alternative to mAb-Based Immunotherapy}

In vitro and in vivo inhibitory effects of $\mathrm{SPD}-1$ shows it can serve a similar function to anti-PD-1 or anti-PD-L1 monoclonal antibodies thereby preventing $\mathrm{PD}-\mathrm{L} 1$ or $\mathrm{PD}-\mathrm{L} 2$ from binding to $\mathrm{mPD}-1$ present on T cells. As such, in vivo inhibitory effects on tumor growth was revealed to be similar to that of anti-PD-L1 $\mathrm{mAb}$ injected mice (103-105). Besides, it can block all three interaction as compared to dual targeting anti-PD-1 and antiPD-L1 mAb thereby enhancing the T cell immunity in direct and indirect manner through blocking B7-1/PD-L1 interaction (114). Additionally, local gene therapy, in general, would have some advantages over antibody-based therapy (135-137). For example, sustained expression of genes would make it costeffective as compared to frequently required high dose injections of mAb $(135,136)$. Similarly, it was found that dosage would not raise concerns about toxic side effects associated with systemic administration of Abs (137). Altogether, advantages of gene-based therapy combined with anti-cancer potential of sPD-1 make this anti-cancer therapeutic strategy more desirable.

\section{Soluble PD-1 in Combination With Other Therapies}

Cancer immune evasion involves development of an immune suppressive tumor microenvironment, reduced immune recognition, increased resistance and survival (138). Hence, therapies could be combined aiming at different aspects of cancer immune evasion. Immune checkpoint blockade has shown limited success due to reinvigoration of existed $\mathrm{T}$ cells. Therapies aimed at increasing antigen production, release and presentation would increase recognition such as RT (139). In addition, vaccination aimed at existed tumor mutations or cytokine therapy are often faced with resistance through upregulation of immune inhibitory checkpoint molecules including PD-1/PD-L1 pathway $(111,119)$. Several animal studies have demonstrated sPD-1 local gene therapy delivery further improving anti-cancer immunity induced by other anti-cancer therapeutics when given in combination or to overcome therapy/ vaccine-induced immune resistance $(104,115-118)$. We will review all various types of combination strategies that could potentially increased sPD-1 anti-cancer effects.

\section{Gene Therapy}

Several factors that can disrupt the cancer immunosuppressive microenvironment may hold potential for anti-cancer gene therapy. Chemokines makes up an important entity of whole immune process particularly in recruiting the immune cells (140). A secondary lymphoid chemokine, CCL21, was evaluated using eukaryotic expression plasmid for local gene therapy (104). In vitro chemokine (pSLC) delivery had induced spleen $\mathrm{T}$ cell migration and in vivo tumor growth inhibition. However, PD-L1, PD-L2 gene expression in tumor cells was observed, and expression was increased with increasing dose of pSLC. Administration of sPD-1 expressing eukaryotic expression plasmid improved the cytotoxicity of tumor-specific CTLs induced by pSLC. Combinatorial local gene transfer was associated with enhanced inhibition of tumor growth with no evidence of autoimmunity.

Similarly, Fibronectin (matrix glycoprotein), an essential component of extracellular matrix is aberrantly expressed in several cancers facilitating tumor growth, invasiveness and metastasis, and resistance to therapy (141). CH50, a recombinant polypeptide with bifunctional domains (CellI and HeparinII), was shown to inhibit tumor growth, metastasis, and regulate macrophages by down-regulation of $\mathrm{CDC} 2, \alpha v \beta 3$ integrin, MMP-2/9 in the tumor microenvironment $(142,143)$. Qiu et al. had constructed a sPD-1-CH50 (a recombinant polypeptide with 3 functional) for anti-cancer immunity evaluation in PD-L1 expressing tumor cells $(116,117)$. sPD-1CH50 had successfully intensified the cytotoxicity of macrophages and CTLs through iNOS, TNF-a, and IFN- $\gamma$. In vivo restriction of hepatoma growth and invasiveness was also demonstrated (116). Inducing thymidine kinase expression in cancer cells through adenoviruses harboring herpes simplex virus thymidine kinase gene (HSVtk), and exposing these expressing cells to ganciclovir (GCV) results in a series of phosphorylation that ultimately leads in cancer cell apoptosis 
(144-147). In vivo and in vitro, it has shown ant-tumor activity probably through improved antigen presentation, which was further enhanced by sPD-1 via enhancing the CD8+ T cells responses (115). Systemic effects of this localized gene delivery were also observed in tumor bearing mice. HSVtk has shown its potential for gene therapy in brain cancer in clinical studies (148). Though, single HSVtk gene therapy has failed to show effectiveness in larger Phase III trials in GBM patients, its potential for combinatorial gene therapy still needs to be evaluated (149, 150). HSVtk and FMS-like tyrosine kinase 3 (FMStk-3, a DC growth factor), in combination had demonstrated anti-tumor adaptive immune responses and cancer cell death in GBM (151). In vivo somatic GM-CSF, IL2 , and HSVtk combination gene therapy had also developed antitumor immunity against non-immunogenic mammary carcinoma (152). Therefore, adding sPD-1 can further enhance the therapeutic effects of these agents in brain cancers as well as other cancers.

\section{Cancer Vaccination}

Several vaccines strategies have been employed against cancer antigens using whole tumor lysates, synthesized peptides, viral vectors with tumor antigens expression, dendritic cells-based vaccination (153). Virus-related cancers such as Human papilloma virus and Epstein-Barr virus have been considered ideal for immunotherapy as foreign antigens are consistently present (154). HPV proteins, E6 and E7, have been used for antitherapeutic vaccines due to their carcinogenicity and foreignness $(155,156)$. HPV therapeutic vaccines are in clinical development for HPV-related precancers cervical intraepithelial neoplasia (CIN) and vulvar intraepithelial neoplasia (VIN) (157). In addition, HPV also have causative association with penile, anal, vulvar, vaginal, oropharyngeal, and laryngeal precancers or cancers (158). Their efficacy has been demonstrated in HPVrelated precancers in comparison to cancers (159). It could be due to several operative immunosuppressive forces including PD-1 and PD-L1 interactions as HPV was itself related to PD-1 and PD-L1/L2 upregulation in HR-HPV+ CIN 1 and CIN 2/3 and metastatic cervical cancer (160). Hence, several animal studies have evaluated the combination of ICBs and E6/E7 vaccine combination resulting in increased CD8+ TILs and suppression of tumor growth (161-165). Soluble PD-1 delivery had also shown enhancement of primary and memory CD8+ T cells mediated anti-tumor immunity induced by human papilloma virus-16 E7 DNA vaccine (111). Furthermore, in vivo maturation of OVA-pulsed BM-DCs cocultured with activated $\mathrm{T}$ cells was accompanied by up-regulation of $\mathrm{DC}$ maturation markers (CD86, CD40, and MHC-II) after being treated with sPD-1 (111). It indicates immunization strategy to increase antigen-specific $\mathrm{T}$ cell immunity induced by vaccination with sPD-1 as an adjuvant.

Therapeutic EBV vaccines have been designed and tested in nasopharyngeal carcinoma (NPC) mainly aimed at EBNA1, LMP2, and have shown immunogenicity by inducing activated CD4+ and CD8+ T cells responses (166). Though, no study has evaluated the use of such vaccines in combination with sPD-1; an inverse proportional relation was observed between sPD-1 and
EBV DNA levels in NPC patients upon IMRT induction (88). After induction of IMRT, survival of patients was prolonged in those who had observed an increase in sPD-1 levels and a decrease in EBV DNA level. The study did not reveal any direct action of sPD-1 on EBV DNA but one may speculate that disrupting the $\mathrm{PD}-1$ pathway may have enhanced the immunity.

Other than viral-related cancers, several other tumorassociated antigens have been evaluated for cancer vaccination such as heat shock proteins (HSP70). HSPs are implicated in cancer growth and resistance to chemotherapy (167, 168). HSP70 and HSP90 vaccines have been evaluated in various trials for its anticancer effectivity in breast cancer, cervical cancer, ovarian, melanoma, renal cell carcinoma, and GBM (169-172). HPS vaccines induced anti-cancer immunity involves the DC maturation, CD8+ and CD4+ T cell-mediated responses, and enhancement of NK cell cytotoxicity (173-180). In an animal study, HSP70 vaccine had induced $\mathrm{T}$ cell infiltration, expression of IFN- $\gamma$ and IL-2, and delaying the pulmonary metastases of melanoma cancer (119). However, an increase in PD-L1 expression was observed in residual tumor cells associated with tumor progression. Addition of sPD-1 successfully overcome the HSP70 vaccine resistance through enhanced expression of IFN- $\gamma$ and IL- 2 genes in tumorinfiltrating lymphocytes and decreased expression of negative regulatory molecules including IL-10, TGF-b, and foxp3. In a similar study, HSP70 vaccine was shown to promote PD-1 and PD-L1 expression in addition to tumor specific cytotoxic $T$ lymphocytes. The combination of sPD-1 and HSP70 further potentiated the immune response. The anti-tumor response of the combination was stronger than each agent alone (120). HSP90 proteins are implicated as oncogenic drivers and its inhibition is sought for anti-cancer therapy (181). Combining HSP90 inhibition with immunotherapy, in particular checkpoint blockade, have also been proposed as they have been associated with induction of PD-1 and its ligands expression $(35,182)$. The combination of a HSP90 inhibitor and an anti-PD-1, PD-L1, and CTLA-4 antibodies have already demonstrated anti-tumor efficacy in preclinical and CRC clinical trials (182, 183). Therefore, sPD-1 delivery along with HSP70/90 vaccines or HSP90 inhibitors holds potential for clinical efficacy.

Recently, senescent cells were used as vaccines as these cells cannot proliferate but still remains metabolically active (184, 185). Accumulation of senescent cells with various SASP (senescence-associated secretory phenotype) could cause proinflammatory microenvironments (185). Nonetheless, the response was restricted by PD-L1 expression. Senescent tumor cell vaccine (STCV) and SPD-1 combination was demonstrated to provide complete protection from 4T1 tumor challenge in mice with pre-injections. Moreover, therapeutic efficacy was also shown by delaying tumorigenesis and suppressing tumor progression at early stages.

\section{T Cell Co-Stimulation}

Anti-cancer immunity by sPD-1 delivery had shown upregulation of costimulatory molecules on splenocytes such as 4-1BB, B7-1, B7-2, and CD40 (103, 111). Qiu, et al. injected 
hepatoma inoculated mice with combinatorial gene for 4-1BB ligand and sPD-1 expression (186). Combined gene expression was associated with enhancement of CD8+ T cells infiltration, greater tumor growth inhibition and improvement in survival of tumor bearing mice $(107,186)$. The observed effect was superior to each gene-effect alone (107). B7-1 upregulation also indicates it may play a similar role and enhancing the receptor for it could result in synergistic response (103). Soluble PD-1 was able to induce DC maturation and expression of B7-2 and CD40 in the presence of DNA vaccine-induced activated T cells (111). B7-2 is a ligand for costimulatory receptor CD28 on T cells while CD40, a DC surface receptor for ligand (CD40L) is expressed on T cells, is essential for DC-mediated $\mathrm{T}$ cell activation. Both of these surface molecules play a critical role in T cell activation. As such, these molecules represent potential targets for gene therapy, much in the same manner as $4-1 \mathrm{BB}$, in combination with sPD1 delivery. Investigation with a greater panel of immune checkpoint modulators during sPD-1 mediated immunity may reveal further therapeutic options for anti-cancer therapy.

\section{Cytokine Therapy}

Cancer cytokine therapy has been developing as more and more agents are being investigated for their clinical efficacy as single agent or in combination with vaccines, immune checkpoint inhibitors or agonist antibodies, and adoptive cell therapy (187). These include IFN- $\alpha$, IFN- $\gamma$, IL-2, IL-7, IL-12, IL-15, IL21 , and Granulocyte-macrophage colony-stimulating factor (GM-CSF). They have shown anti-tumor responses in animal models as well as clinical trials by stimulating effector cells including $\mathrm{T}$ cells and NK cells. Several of these cytokines were shown to up-regulate PD-1 on T cells such as IL-2, IL-7, IL-15, and IL-21 (32). Cytokines are also associated with up-regulation of PD-L1 with the exception of IL-21. Pan, et al. evaluated the effects of sPD-1 combined with IL-21 therapy in a hepatoma murine model (121). The anti-cancer immunity was enhanced by the combined treatment and significantly inhibited the tumor growth in comparison to IL-21 alone. Enhancement was demonstrated in form of increase in CTL cytotoxicity, numbers of CTLs and NK cells, and upregulation of cytokines such as IFN- $\gamma$ and IL-2 with downregulation of IL-10.

\section{PD-L1 Expression Regulating Molecules}

PD-L1 expression is regulated on tumor cells at many levels including genomic, transcriptional, epigenetic, and translational level $(188,189)$. These regulators include cytokines, intracellular oncoproteins, and microRNAs that regulate $\mathrm{PD}-\mathrm{L} 1$ regulation positively or negatively in a direct or indirect manner $(188,189)$. For-example, it has been acknowledged that PD-L1 was upregulated by p53 via miR-34 (54). Such a combination of PDL1 upregulation and miR-34 down-regulation revealed in cervical cancer was exploited by Qin et al. for synergistic anti-cancer responses (190-192). Qin, et al. prepared Cationic lipid microbubbles (CLMBs) loaded with sPD-1 and miR-34a in combination with ultrasound targeted destruction (192). Ultrasound-mediated co-delivery of sPD-1 and miR-34a successfully decreased tumor volume and weight by inducing apoptosis as revealed by downregulation of suppressor gene Bcl-2 and upregulation of proapoptotic gene Bax. Antitumor immunityrelated IFN- $\gamma$ was strongly upregulated and percentage of CTL was also increased. On the other hand, tumor deficient in PD-L1 expression contribute to "target missing" resistance (193). In this sense, positive PD-L1 regulators (epigenetic or some treatments like $\mathrm{RT}$ ), through upregulation of PD-L1, may be used in combination with ICB or sPD-1 for synergistic anti-tumor effect.

\section{Immune Checkpoint Blockade Immunotherapy}

Monoclonal antibody-based immune checkpoint blockade has emerged as an attractive, promising anti-cancer strategy aimed at enhancing anti-cancer T lymphocytes $(194,195)$. The clinical results from the already FDA-approved ICB agents including ipilimumab (anti-CTLA-4 mAb), nivolumab, pembrolizumab (anti-PD-1 mAbs), atezolizumab, avelumab, and durvalumab (anti-PD-L1 mAbs) are unprecedent and encouraging (194, 195). Though, both checkpoint blockades (anti-CTLA-4 and $\mathrm{PD}-1 / \mathrm{PD}-\mathrm{L} 1)$ rescues anti-tumor $\mathrm{T}$ lymphocytes, they are thought to affect different phases of anti-tumor $\mathrm{T}$ cell responses (194). Checkpoint blockade of CTLA-4 supports induction phase while PD-1/PD-L1 blockade maintains effector phase of anti-tumor cell responses (194). Therefore, in various cancers, combination of these ICB agents have already been approved (advanced melanoma, renal cell carcinoma) or investigated (NSCLC, recurrent SCLC) for clinical synergy (196-200). Soluble PD-1 gene therapy, in the same manner, may also finds a natural partner in anti-CTLA-4 agents for synergistic immune responses. Delivery of sPD-1 along with antiPD-1/PD-L1 mAbs may show synergistic effects. As direct local tumor delivery may further enhance anti-tumor response due to elevation of local levels of sPD-1 as PD-1 mediated inhibition strength differentially affects $\mathrm{T}$ cell effector functions (45). Simultaneously, higher doses of mAb could be prevented to reach greater efficacy as higher systemic doses are associated with increased side effects. Circulating sPD-L1 plasma level is associated with cancer prognosis, and has been shown to inversely affect the efficacy of anti-PD-1 (nivolumab) $\mathrm{mAb}$ in cancer patients $(122,128,129)$. Higher sPD-L1 levels were associated with lower nivolumab efficacy and worst prognosis (17, 122). Hence, administration of sPD-1 may interfere with the circulating sPD-L1 thereby reducing its inhibitory action and enhance efficacy of anti-PD-1 mAb. As such, post-therapy increase in SPD-1 level was associated improved survival after two cycles of anti-PD-1 mAb (87). On the other hand, sPD-1 and anti$\mathrm{PD}-\mathrm{L} 1 \mathrm{mAb}$ have the same targets (mPD-L1 and sPD-L1) thereby sPD-1 delivery could increase its efficacy and reduce toxicity associated with $\mathrm{mAbs}$ by reducing doses of $\mathrm{mAb}$ injections (127). Scope of immune checkpoints is quickly expanding as newer checkpoints such as TIGIT, TIM-3, LAG-3, VISTA, BTLA, B7$\mathrm{H} 3$ etcetera, are being discovered and some of them (TIGIT, TIM-3, and $\mathrm{B} 7-\mathrm{H} 3$ ) are expressed in combination with $\mathrm{PD}-1$ regulating not only T cells but also NK cells (201-210). These checkpoints also hold potential for combination ICB strategy with sPD-1.

\section{Other Conventional Anti-Cancer Therapies}

Radiotherapy induces anti-tumor immune response through several mechanisms such as increase in pro-inflammatory cytokines, 
antigen release from irradiated cells to prime tumor-specific T cell responses, enhancing $\mathrm{T}$ cell infiltration into tumors (100, 101, 188, 189). Yet, these anti-tumor immune responses may be blunted by several mechanisms including regulatory $\mathrm{T}$ cells and checkpoint molecules such as PD-L1 that promote $\mathrm{T}$ cell tolerance and exhaustion. Radiotherapy plus immunotherapy has been revealed in several studies to have synergistic efficacy in treating cancer patients $(211,212)$. Chemotherapy has also been revealed to reduce regulatory $\mathrm{T}$ cell activity, increase ratio of CTL to Tregs, inhibits myeloid-derived suppressor cells, increase antigen presentation, and up-regulate PD-L1 expression (213-218). And so, it has been combined with ICB in lung cancer and revealed to have better efficacy (219). Plasma levels of PD-L1 has also been associated with prognosis in cancer patients receiving radiotherapy or chemotherapy (130-134). Therefore, sPD-1 delivery could have synergistic ant-cancer effects in combination with these treatments.

\section{CONCLUSIONS}

Blockade of PD-1/PD-L1 inhibitory immune checkpoint have revolutionized the cancer therapy paradigm; hence, this particular checkpoint pathway has been the subject of intense investigations. Expression, regulation, and interaction of PD-1 and its ligands have enhanced our understanding of how costimulatory and coinhibitory molecules have been exploited by cancer cells for immune evasion. In recent times, a surge in investigations of soluble forms of these molecules detected in the plasma of cancer patients have been observed. These investigations have been mainly focused on the predictive and prognostic values of these molecules. Several studies have revealed that both, sPD-1 and SPD-L1, are elevated in cancer patients and may predict worst prognosis. Production of both molecules is correlated during the course of the disease and may have same provenience. Soluble forms may be produced in order to maintain peripheral self-tolerance and immune evasion. Disrupting this balance by increasing the amount of sPD-1 or sPD-L1 may shift immune balance; enhancing T cell activation through disrupting PD-1/PD-L1 interaction by $\mathrm{PPD}-1$, or $\mathrm{T}$ cell

\section{REFERENCES}

1. Garcia KC. Dual Arms of Adaptive Immunity: Division of Labor and Collaboration between B and T Cells. Cell (2019) 179(1):3-7. doi: 10.1016/j.cell.2019.08.022

2. Smith-Garvin JE, Koretzky GA, Jordan MS. T cell activation. Annu Rev Immunol (2009) 27:591-619. doi: 10.1146/annurev.immunol.021908.132706

3. Bell E. T-cell-APC interactions. Nat Rev Immunol (2004) 4(12):930-. doi: $10.1038 /$ nri1515

4. Esensten JH, Helou YA, Chopra G, Weiss A, Bluestone JA. CD28 Costimulation: From Mechanism to Therapy. Immunity (2016) 44 (5):973-88. doi: 10.1016/j.immuni.2016.04.020

5. Gibson HM, Hedgcock CJ, Aufiero BM, Wilson AJ, Hafner MS, Tsokos GC, et al. Induction of the CTLA-4 Gene in Human Lymphocytes Is Dependent on NFAT Binding the Proximal Promoter. J Immunol (2007) 179(6):3831. doi: 10.4049/jimmunol.179.6.3831 inhibition through increased expression of sPD-L1. Such effects are observed in clinical studies. Such as, therapeutic intervention may increase or decrease the level of each molecule, in particular, post therapeutic increase in sPD-1 levels was associated with improved outcome. Also, elevated levels of sPD-L1 are associated with worst outcome and decreased efficacy of anti-PD-1 mAb $(17,122)$. While increase in sPD-1 was associated with better efficacy of anti-PD-1 mAb (nivolumab) (87). As sPD-1 retain its ability to bind its ligands can, therefore, interrupt PD-1/PD-L1 pathway. As such, sPD-1 may be used as a therapeutic strategy for interrupting PD-L1 interactions in the same manner as monoclonal antibodies. Several in vitro and in vivo studies have shown that increasing sPD-1 in tumor microenvironment can successfully induce anti-tumor immunity and reduce the cancer growth. Furthermore, it has also shown synergy with several other anti-cancer therapeutic strategies in the same manner as ICB. Also, it can enhance the potential of cancer vaccination and overcome its resistance. It can also be used to overcome cancer therapy resistance as PD-L1 up-regulation is one of the resistance mechanisms implied by cancers. So far, only animal studies have evaluated its candidacy for anti-cancer therapy potential. Given its broad anti-cancer therapeutic potential, it might be the time, the application of $s \mathrm{PD}-1$ as an anti-cancer therapy be evaluated in clinic.

\section{AUTHOR CONTRIBUTIONS}

All authors have contributed equally. All authors contributed to the article and approved the submitted version.

\section{FUNDING}

This work was supported by the Natural Science Foundation of Shenzhen (No. JCYJ20170307095828424), Shenzhen Health and Family Planning System Research Project (No. SZBC2017024), and the technical research and cultivation project for the youth of Shenzhen People's Hospital (No. SYKYPY2019029).
6. Teft WA, Kirchhof MG, Madrenas J. A molecular perspective of CTLA-4 function. Annu Rev Immunol (2006) 24:65-97. doi: 10.1146/ annurev.immunol.24.021605.090535

7. Dong Y, Sun Q, Zhang X. PD-1 and its ligands are important immune checkpoints in cancer. Oncotarget (2017) 8(2):2171-86. doi: 10.18632/ oncotarget.13895

8. Zak KM, Grudnik P, Magiera K, Dömling A, Dubin G, Holak TA. Structural Biology of the Immune Checkpoint Receptor PD-1 and Its Ligands PD-L1/ PD-L2. Structure (2017) 25(8):1163-74. doi: 10.1016/j.str.2017.06.011

9. Freeman GJ, Long AJ, Iwai Y, Bourque K, Chernova T, Nishimura H, et al. Engagement of the PD-1 immunoinhibitory receptor by a novel B7 family member leads to negative regulation of lymphocyte activation. J Exp Med (2000) 192(7):1027-34. doi: 10.1084/jem.192.7.1027

10. Wang L, Pino-Lagos K, de Vries VC, Guleria I, Sayegh MH, Noelle RJ. Programmed death 1 ligand signaling regulates the generation of adaptive Foxp3+CD4+ regulatory T cells. Proc Natl Acad Sci U S A (2008) 105 (27):9331-6. doi: 10.1073/pnas.0710441105 
11. Pauken KE, Wherry EJ. Overcoming T cell exhaustion in infection and cancer. Trends Immunol (2015) 36(4):265-76. doi: 10.1016/j.it.2015.02.008

12. Jiang X, Wang J, Deng X, Xiong F, Ge J, Xiang B, et al. Role of the tumor microenvironment in PD-L1/PD-1-mediated tumor immune escape. Mol Cancer (2019) 18(1):10. doi: 10.1186/s12943-018-0928-4

13. Zitvogel L, Kroemer G. Targeting PD-1/PD-L1 interactions for cancer immunotherapy. Oncoimmunology (2012) 1(8):1223-5. doi: 10.4161/ onci.21335

14. Darvin P, Toor SM, Sasidharan Nair V, Elkord E. Immune checkpoint inhibitors: recent progress and potential biomarkers. Exp Mol Med (2018) 50 (12):165. doi: 10.1038/s12276-018-0191-1

15. Iwai Y, Hamanishi J, Chamoto K, Honjo T. Cancer immunotherapies targeting the PD-1 signaling pathway. J Biomed Sci (2017) 24(1):26. doi: 10.1186/s12929-017-0329-9

16. Sharpe AH, Pauken KE. The diverse functions of the PD1 inhibitory pathway. Nat Rev Immunol (2018) 18(3):153-67. doi: 10.1038/nri.2017.108

17. Ugurel S, Schadendorf D, Horny K, Sucker A, Schramm S, Utikal J, et al. Elevated baseline serum PD-1 or PD-L1 predicts poor outcome of PD-1 inhibition therapy in metastatic melanoma. Ann Oncol (2020) 31(1):144-52. doi: 10.1016/j.annonc.2019.09.005

18. Zhu X, Lang J. Soluble PD-1 and PD-L1: predictive and prognostic significance in cancer. Oncotarget (2017) 8(57):97671-82. doi: 10.18632/ oncotarget.18311

19. Gu D, Ao X, Yang Y, Chen Z, Xu X. Soluble immune checkpoints in cancer: production, function and biological significance. J Immunother Cancer (2018) 6(1):132-. doi: 10.1186/s40425-018-0449-0

20. Takeuchi M, Doi T, Obayashi K, Hirai A, Yoneda K, Tanaka F, et al. Soluble PD-L1 with PD-1-binding capacity exists in the plasma of patients with nonsmall cell lung cancer. Immunol Lett (2018) 196:155-60. doi: 10.1016/ j.imlet.2018.01.007

21. Zhang X, Schwartz JC, Guo X, Bhatia S, Cao E, Lorenz M, et al. Structural and functional analysis of the costimulatory receptor programmed death-1. Immunity (2004) 20(3):337-47. doi: 10.1016/s1074-7613(04)00051-2

22. Schildberg FA, Klein SR, Freeman GJ, Sharpe AH. Coinhibitory Pathways in the B7-CD28 Ligand-Receptor Family. Immunity (2016) 44(5):955-72. doi: 10.1016/j.immuni.2016.05.002

23. Ishida $\mathrm{Y}$, Agata $\mathrm{Y}$, Shibahara K, Honjo T. Induced expression of PD-1, a novel member of the immunoglobulin gene superfamily, upon programmed cell death. ЕMBO J (1992) 11(11):3887-95. doi: 10.1002/j.14602075.1992.tb05481.x

24. Boussiotis VA. Molecular and Biochemical Aspects of the PD-1 Checkpoint Pathway. N Engl J Med (2016) 375(18):1767-78. doi: 10.1056/NEJMra1514296

25. Carreno BM, Collins M. The B7 family of ligands and its receptors: new pathways for costimulation and inhibition of immune responses. Annu Rev Immunol (2002) 20:29-53. doi: 10.1146/annurev.immunol.20.091101.091806

26. Neel BG, Gu H, Pao L. The 'Shp'ing news: SH2 domain-containing tyrosine phosphatases in cell signaling. Trends Biochem Sci (2003) 28(6):284-93. doi: 10.1016/s0968-0004(03)00091-4

27. Keir ME, Francisco LM, Sharpe AH. PD-1 and its ligands in T-cell immunity. Curr Opin Immunol (2007) 19(3):309-14. doi: 10.1016/ j.coi.2007.04.012

28. Keir ME, Butte MJ, Freeman GJ, Sharpe AH. PD-1 and its ligands in tolerance and immunity. Annu Rev Immunol (2008) 26:677-704. doi: 10.1146/annurev.immunol.26.021607.090331

29. Terawaki S, Chikuma S, Shibayama S, Hayashi T, Yoshida T, Okazaki T, et al. IFN- $\alpha$ directly promotes programmed cell death-1 transcription and limits the duration of T cell-mediated immunity. J Immunol (2011) 186 (5):2772-9. doi: 10.4049/jimmunol.1003208

30. Cho HY, Lee SW, Seo SK, Choi IW, Choi I, Lee SW. Interferon-sensitive response element (ISRE) is mainly responsible for IFN-alpha-induced upregulation of programmed death-1 (PD-1) in macrophages. Biochim Biophys Acta (2008) 1779(12):811-9. doi: 10.1016/j.bbagrm.2008.08.003

31. Austin JW, Lu P, Majumder P, Ahmed R, Boss JM. STAT3, STAT4, NFATc1, and CTCF regulate PD-1 through multiple novel regulatory regions in murine T cells. J Immunol (2014) 192(10):4876-86. doi: $10.4049 /$ jimmunol.1302750

32. Kinter AL, Godbout EJ, McNally JP, Sereti I, Roby GA, O'Shea MA, et al. The common gamma-chain cytokines IL-2, IL-7, IL-15, and IL-21 induce the expression of programmed death-1 and its ligands. J Immunol (2008) 181 (10):6738-46. doi: 10.4049/jimmunol.181.10.6738

33. Green MR, Monti S, Rodig SJ, Juszczynski P, Currie T, O’Donnell E, et al. Integrative analysis reveals selective 9p24.1 amplification, increased PD-1 ligand expression, and further induction via JAK2 in nodular sclerosing Hodgkin lymphoma and primary mediastinal large B-cell lymphoma. Blood (2010) 116(17):3268-77. doi: 10.1182/blood-2010-05-282780

34. Marzec M, Zhang Q, Goradia A, Raghunath PN, Liu X, Paessler M, et al. Oncogenic kinase NPM/ALK induces through STAT3 expression of immunosuppressive protein CD274 (PD-L1, B7-H1). Proc Natl Acad Sci USA (2008) 105(52):20852-7. doi: 10.1073/pnas.0810958105

35. Noman MZ, Desantis G, Janji B, Hasmim M, Karray S, Dessen P, et al. PDL1 is a novel direct target of HIF-1 $\alpha$, and its blockade under hypoxia enhanced MDSC-mediated T cell activation. J Exp Med (2014) 211(5):78190. doi: $10.1084 /$ jem. 20131916

36. Zhang N, Zeng Y, Du W, Zhu J, Shen D, Liu Z, et al. The EGFR pathway is involved in the regulation of PD-L1 expression via the IL-6/JAK/STAT3 signaling pathway in EGFR-mutated non-small cell lung cancer. Int J Oncol (2016) 49(4):1360-8. doi: 10.3892/ijo.2016.3632

37. Akbay EA, Koyama S, Carretero J, Altabef A, Tchaicha JH, Christensen CL, et al. Activation of the PD-1 pathway contributes to immune escape in EGFR-driven lung tumors. Cancer Discovery (2013) 3(12):1355-63. doi: 10.1158/2159-8290.Cd-13-0310

38. Ota K, Azuma K, Kawahara A, Hattori S, Iwama E, Tanizaki J, et al. Induction of PD-L1 Expression by the EML4-ALK Oncoprotein and Downstream Signaling Pathways in Non-Small Cell Lung Cancer. Clin Cancer Res Off J Am Assoc Cancer Res (2015) 21(17):4014-21. doi: 10.1158/1078-0432.Ccr-15-0016

39. Shen MJ, Xu LJ, Yang L, Tsai Y, Keng PC, Chen Y, et al. Radiation alters PDL1/NKG2D ligand levels in lung cancer cells and leads to immune escape from NK cell cytotoxicity via IL-6-MEK/Erk signaling pathway. Oncotarget (2017) 8(46):80506-20. doi: 10.18632/oncotarget.19193

40. Xu L, Chen X, Shen M, Yang DR, Fang L, Weng G, et al. Inhibition of IL-6JAK/Stat3 signaling in castration-resistant prostate cancer cells enhances the NK cell-mediated cytotoxicity via alteration of PD-L1/NKG2D ligand levels. Mol Oncol (2018) 12(3):269-86. doi: 10.1002/1878-0261.12135

41. Wang X, Ni S, Chen Q, Ma L, Jiao Z, Wang C, et al. Bladder cancer cells induce immunosuppression of T cells by supporting PD-L1 expression in tumour macrophages partially through interleukin 10. Cell Biol Int (2017) 41 (2):177-86. doi: 10.1002/cbin.10716

42. Xiong HY, Ma TT, Wu BT, Lin Y, Tu ZG. IL-12 regulates B7-H1 expression in ovarian cancer-associated macrophages by effects on NF- $\mathrm{KB}$ signalling. Asian Pac J Cancer Prev APJCP (2014) 15(14):5767-72. doi: 10.7314/ apjcp.2014.15.14.5767

43. Wang WB, Yen ML, Liu KJ, Hsu PJ, Lin MH, Chen PM, et al. Interleukin-25 Mediates Transcriptional Control of PD-L1 via STAT3 in Multipotent Human Mesenchymal Stromal Cells (hMSCs) to Suppress Th17 Responses. Stem Cell Rep (2015) 5(3):392-404. doi: 10.1016/ j.stemcr.2015.07.013

44. Carbotti G, Barisione G, Airoldi I, Mezzanzanica D, Bagnoli M, Ferrero S, et al. IL-27 induces the expression of IDO and PD-L1 in human cancer cells. Oncotarget (2015) 6(41):43267-80. doi: 10.18632/oncotarget.6530

45. Fang W, Zhang J, Hong S, Zhan J, Chen N, Qin T, et al. EBV-driven LMP1 and IFN- $\gamma$ up-regulate PD-L1 in nasopharyngeal carcinoma: Implications for oncotargeted therapy. Oncotarget (2014) 5(23):12189-202. doi: 10.18632/oncotarget.2608

46. Derks S, Liao X, Chiaravalli AM, Xu X, Camargo MC, Solcia E, et al. Abundant PD-L1 expression in Epstein-Barr Virus-infected gastric cancers. Oncotarget (2016) 7(22):32925-32. doi: 10.18632/oncotarget.9076

47. Kathuria H, Millien G, McNally L, Gower AC, Tagne JB, Cao Y, et al. NKX21-AS1 negatively regulates CD274/PD-L1, cell-cell interaction genes, and limits human lung carcinoma cell migration. Sci Rep (2018) 8(1):14418. doi: 10.1038/s41598-018-32793-5

48. Chen J, Jiang CC, Jin L, Zhang XD. Regulation of PD-L1: a novel role of prosurvival signalling in cancer. Ann Oncol Off J Eur Soc Med Oncol (2016) 27 (3):409-16. doi: 10.1093/annonc/mdv615

49. Chen L, Gibbons DL, Goswami S, Cortez MA, Ahn YH, Byers LA, et al. Metastasis is regulated via microRNA-200/ZEB1 axis control of tumour cell 
PD-L1 expression and intratumoral immunosuppression. Nat Commun (2014) 5:5241. doi: 10.1038/ncomms6241

50. Gong AY, Zhou R, Hu G, Li X, Splinter PL, O’Hara SP, et al. MicroRNA-513 regulates $\mathrm{B} 7-\mathrm{H} 1$ translation and is involved in IFN-gamma-induced B7-H1 expression in cholangiocytes. J Immunol (2009) 182(3):1325-33. doi: 10.4049/jimmunol.182.3.1325

51. Yee D, Shah KM, Coles MC, Sharp TV, Lagos D. MicroRNA-155 induction via TNF- $\alpha$ and IFN- $\gamma$ suppresses expression of programmed death ligand-1 (PD-L1) in human primary cells. J Biol Chem (2017) 292(50):20683-93. doi: 10.1074/jbc.M117.809053

52. Xie G, Li W, Li R, Wu K, Zhao E, Zhang Y, et al. Helicobacter Pylori Promote B7-H1 Expression by Suppressing miR-152 and miR-200b in Gastric Cancer Cells. PloS One (2017) 12(1):e0168822. doi: 10.1371/journal.pone.0168822

53. Wang W, Li F, Mao Y, Zhou H, Sun J, Li R, et al. A miR-570 binding site polymorphism in the $\mathrm{B} 7-\mathrm{H} 1$ gene is associated with the risk of gastric adenocarcinoma. Hum Genet (2013) 132(6):641-8. doi: 10.1007/s00439013-1275-6

54. Cortez MA, Ivan C, Valdecanas D, Wang X, Peltier HJ, Ye Y, et al. PDL1 Regulation by p53 via miR-34. J Natl Cancer Inst (2016) 108(1):djv303. doi: 10.1093/jnci/djv303

55. Sheppard KA, Fitz LJ, Lee JM, Benander C, George JA, Wooters J, et al. PD-1 inhibits T-cell receptor induced phosphorylation of the ZAP70/CD3zeta signalosome and downstream signaling to PKCtheta. FEBS Lett (2004) 574 (1-3):37-41. doi: 10.1016/j.febslet.2004.07.083

56. Patsoukis N, Brown J, Petkova V, Liu F, Li L, Boussiotis VA. Selective effects of PD-1 on Akt and Ras pathways regulate molecular components of the cell cycle and inhibit T cell proliferation. Sci Signal (2012) 5(230):ra46. doi: 10.1126/scisignal.2002796

57. Chemnitz JM, Parry RV, Nichols KE, June CH, Riley JL. SHP-1 and SHP-2 associate with immunoreceptor tyrosine-based switch motif of programmed death 1 upon primary human $\mathrm{T}$ cell stimulation, but only receptor ligation prevents T cell activation. J Immunol (2004) 173(2):945-54. doi: 10.4049/ jimmunol.173.2.945

58. Vazquez F, Ramaswamy S, Nakamura N, Sellers WR. Phosphorylation of the PTEN tail regulates protein stability and function. Mol Cell Biol (2000) 20 (14):5010-8. doi: $10.1128 / \mathrm{mcb} .20 .14 .5010-5018.2000$

59. Torres J, Pulido R. The tumor suppressor PTEN is phosphorylated by the protein kinase CK2 at its C terminus. Implications for PTEN stability to proteasome-mediated degradation. J Biol Chem (2001) 276(2):993-8. doi: 10.1074/jbc.M009134200

60. Patsoukis N, Li L, Sari D, Petkova V, Boussiotis VA. PD-1 increases PTEN phosphatase activity while decreasing PTEN protein stability by inhibiting casein kinase 2. Mol Cell Biol (2013) 33(16):3091-8. doi: 10.1128/ mcb.00319-13

61. MacIver NJ, Michalek RD, Rathmell JC. Metabolic regulation of $\mathrm{T}$ lymphocytes. Annu Rev Immunol (2013) 31:259-83. doi: 10.1146/ annurev-immunol-032712-095956

62. Frauwirth KA, Thompson CB. Regulation of T Lymphocyte Metabolism. J Immunol (2004) 172(8):4661. doi: 10.4049/jimmunol.172.8.4661

63. Wieman HL, Wofford JA, Rathmell JC. Cytokine stimulation promotes glucose uptake via phosphatidylinositol-3 kinase/Akt regulation of Glut1 activity and trafficking. Mol Biol Cell (2007) 18(4):1437-46. doi: 10.1091/ mbc.e06-07-0593

64. Patsoukis N, Bardhan K, Chatterjee P, Sari D, Liu B, Bell LN, et al. PD-1 alters T-cell metabolic reprogramming by inhibiting glycolysis and promoting lipolysis and fatty acid oxidation. Nat Commun (2015) 6:6692. doi: $10.1038 /$ ncomms7692

65. Jaudszus A, Gruen M, Watzl B, Ness C, Roth A, Lochner A, et al. Evaluation of suppressive and pro-resolving effects of EPA and DHA in human primary monocytes and T-helper cells. J Lipid Res (2013) 54(4):923-35. doi: 10.1194/ jlr.P031260

66. Bivona TG, Pérez De Castro I, Ahearn IM, Grana TM, Chiu VK, Lockyer PJ, et al. Phospholipase Cgamma activates Ras on the Golgi apparatus by means of RasGRP1. Nature (2003) 424(6949):694-8. doi: 10.1038/nature01806

67. Macian F. NFAT proteins: key regulators of T-cell development and function. Nat Rev Immunol (2005) 5(6):472-84. doi: 10.1038/nri1632

68. Karwacz K, Bricogne C, MacDonald D, Arce F, Bennett CL, Collins M, et al. PD-L1 co-stimulation contributes to ligand-induced T cell receptor down- modulation on CD8+ T cells. EMBO Mol Med (2011) 3(10):581-92. doi: $10.1002 / \mathrm{emmm} .201100165$

69. Fang D, Liu YC. Proteolysis-independent regulation of PI3K by Cbl-bmediated ubiquitination in T cells. Nat Immunol (2001) 2(9):870-5. doi: 10.1038/ni0901-870

70. Guo H, Qiao G, Ying H, Li Z, Zhao Y, Liang Y, et al. E3 ubiquitin ligase Cbl-b regulates Pten via Nedd4 in T cells independently of its ubiquitin ligase activity. Cell Rep (2012) 1(5):472-82. doi: 10.1016/j.celrep.2012.04.008

71. Jeon MS, Atfield A, Venuprasad K, Krawczyk C, Sarao R, Elly C, et al. Essential role of the $\mathrm{E} 3$ ubiquitin ligase Cbl-b in T cell anergy induction. Immunity (2004) 21(2):167-77. doi: 10.1016/j.immuni.2004.07.013

72. Tang R, Langdon WY, Zhang J. Regulation of immune responses by E3 ubiquitin ligase Cbl-b. Cell Immunol (2019) 340:103878-. doi: 10.1016/ j.cellimm.2018.11.002

73. Quigley M, Pereyra F, Nilsson B, Porichis F, Fonseca C, Eichbaum Q, et al. Transcriptional analysis of HIV-specific CD8+ T cells shows that PD-1 inhibits T cell function by upregulating BATF. Nat Med (2010) 16(10):114751. doi: $10.1038 / \mathrm{nm} .2232$

74. Azuma T, Yao S, Zhu G, Flies AS, Flies SJ, Chen L. B7-H1 is a ubiquitous antiapoptotic receptor on cancer cells. Blood (2008) 111(7):3635-43. doi: 10.1182/blood-2007-11-123141

75. Chang CH, Qiu J, O'Sullivan D, Buck MD, Noguchi T, Curtis JD, et al. Metabolic Competition in the Tumor Microenvironment Is a Driver of Cancer Progression. Cell (2015) 162(6):1229-41. doi: 10.1016/ j.cell.2015.08.016

76. Kuipers H, Muskens F, Willart M, Hijdra D, van Assema FB, Coyle AJ, et al. Contribution of the PD-1 ligands/PD-1 signaling pathway to dendritic cellmediated CD4+ T cell activation. Eur J Immunol (2006) 36(9):2472-82. doi: $10.1002 /$ eji.200635978

77. Dong M, Enomoto M, Le T, Hai H, Hieu V, Hoang D, et al. Clinical significance of circulating soluble immune checkpoint proteins in sorafenibtreated patients with advanced hepatocellular carcinoma. Sci Rep (2020) 10:3392. doi: 10.1038/s41598-020-60440-5

78. Hock BD, McKenzie JL, Patton NW, Drayson M, Taylor K, Wakeman C, et al. Circulating levels and clinical significance of soluble CD40 in patients with hematologic malignancies. Cancer (2006) 106(10):2148-57. doi: $10.1002 /$ cncr.21816

79. Jeannin P, Magistrelli G, Aubry JP, Caron G, Gauchat JF, Renno T, et al. Soluble CD86 is a costimulatory molecule for human T lymphocytes. Immunity (2000) 13(3):303-12. doi: 10.1016/s1074-7613(00)00030-3

80. Nielsen C, Ohm-Laursen L, Barington T, Husby S, Lillevang ST. Alternative splice variants of the human PD-1 gene. Cell Immunol (2005) 235(2):109-16. doi: 10.1016/j.cellimm.2005.07.007

81. Li N, Zhou Z, Li F, Sang J, Han Q, Lv Y, et al. Circulating soluble programmed death-1 levels may differentiate immune-tolerant phase from other phases and hepatocellular carcinoma from other clinical diseases in chronic hepatitis B virus infection. Oncotarget (2017) 8(28):46020-33. doi: 10.18632/oncotarget.17546

82. Incorvaia L, Badalamenti G, Rinaldi G, Iovanna JL, Olive D, Swayden M, et al. Can the plasma PD-1 levels predict the presence and efficiency of tumorinfiltrating lymphocytes in patients with metastatic melanoma? Ther Adv Med Oncol (2019) 11:1758835919848872. doi: 10.1177/1758835919848872

83. Kruger S, Legenstein M-L, Rösgen V, Haas M, Modest DP, Westphalen CB, et al. Serum levels of soluble programmed death protein 1 (sPD-1) and soluble programmed death ligand 1 (sPD-L1) in advanced pancreatic cancer. Oncoimmunology (2017) 6(5):e1310358-e. doi: 10.1080/2162402X.2017.1310358

84. Bian B, Fanale D, Dusetti N, Roque J, Pastor S, Chretien A-S, et al. Prognostic significance of circulating PD-1, PD-L1, pan-BTN3As, BTN3A1 and BTLA in patients with pancreatic adenocarcinoma. OncoImmunology (2019) 8(4): e1561120. doi: 10.1080/2162402X.2018.1561120

85. Abu Hejleh T, Furqan M, Ballas Z, Clamon G. The clinical significance of soluble PD-1 and PD-L1 in lung cancer. Crit Rev Oncol Hematol (2019) 143:148-52. doi: 10.1016/j.critrevonc.2019.08.009

86. Chang B, Huang T, Wei H, Shen L, Zhu D, He W, et al. The correlation and prognostic value of serum levels of soluble programmed death protein 1 (sPD-1) and soluble programmed death-ligand 1 (sPD-L1) in patients with hepatocellular carcinoma. Cancer Immunol Immunother (2019) 68(3):35363. doi: $10.1007 / \mathrm{s} 00262-018-2271-4$ 
87. Tiako Meyo M, Jouinot A, Giroux-Leprieur E, Fabre E, Wislez M, Alifano M, et al. Predictive Value of Soluble PD-1, PD-L1, VEGFA, CD40 Ligand and CD44 for Nivolumab Therapy in Advanced Non-Small Cell Lung Cancer: A CaseControl Study. Cancers (2020) 12(2):473. doi: 10.3390/cancers12020473

88. Ruan Y, Hu W, Li W, Lu H, Gu H, Zhang Y, et al. Analysis of Plasma EBVDNA and Soluble Checkpoint Proteins in Nasopharyngeal Carcinoma Patients after Definitive Intensity-Modulated Radiotherapy. BioMed Res Int (2019) 2019:9. doi: 10.1155/2019/3939720

89. Cheng HY, Kang PJ, Chuang YH, Wang YH, Jan MC, Wu CF, et al. Circulating programmed death-1 as a marker for sustained high hepatitis B viral load and risk of hepatocellular carcinoma. PloS One (2014) 9(11): e95870. doi: 10.1371/journal.pone.0095870

90. Mortensen JB, Hansen IM, Clausen MR, Bjerre M, Amore F. Elevated PreTherapeutic Serum Levels of Soluble Programmed Death 1 Protein (sPD-1) Identify DLBCL Patients with Adverse Prognostic Features. Blood (2017) 130(Suppl 1):4148. doi: 10.1182/blood.V130.Suppl_1.4148.4148

91. Sorensen SF, Demuth C, Weber B, Sorensen BS, Meldgaard P. Increase in soluble PD-1 is associated with prolonged survival in patients with advanced EGFR-mutated non-small cell lung cancer treated with erlotinib. Lung Cancer (Amsterdam Netherlands) (2016) 100:77-84. doi: 10.1016/ j.lungcan.2016.08.001

92. Tominaga T, Akiyoshi T, Yamamoto N, Taguchi S, Mori S, Nagasaki T, et al. Clinical significance of soluble programmed cell death-1 and soluble programmed cell death-ligand 1 in patients with locally advanced rectal cancer treated with neoadjuvant chemoradiotherapy. PloS One (2019) 14: e0212978. doi: 10.1371/journal.pone.0212978

93. Jubel JM, Barbati ZR, Burger C, Wirtz DC, Schildberg FA. The Role of PD-1 in Acute and Chronic Infection. Front Immunol (2020) 11:487. doi: 10.3389/ fimmu.2020.00487

94. Aarslev K, Dige A, Greisen SR, Kreutzfeldt M, Jessen N, Vilstrup H, et al. Soluble programmed death-1 levels are associated with disease activity and treatment response in patients with autoimmune hepatitis. Scand $J$ Gastroenterol (2017) 52(1):93-9. doi: 10.1080/00365521.2016.1233576

95. reisen SR, Rasmussen TK, Stengaard-Pedersen K, Hetland ML, HørslevPetersen K, Hvid M, et al. Increased soluble programmed death-1 (sPD-1) is associated with disease activity and radiographic progression in early rheumatoid arthritis. Scand J Rheumatol (2014) 43(2):101-8. doi: 10.3109/ 03009742.2013.823517

96. Jovanovic D, Roksandic Milenkovic M, Kotur Stevuljevic J, Markovic J, Ceriman V, Kontic M, et al. Membrane PD-L1 expression and soluble PDL1 plasma levels in idiopathic pulmonary fibrosis-a pilot study. J Thorac Dis (2018) 10(12):6660-9. doi: 10.21037/jtd.2018.11.16

97. Jiao Q, Liu C, Yang Z, Ding Q, Wang M, Li M, et al. Upregulated PD-1 Expression Is Associated with the Development of Systemic Lupus Erythematosus, but Not the PD-1.1 Allele of the PDCD1 Gene. Int J Genomics (2014) 2014:950903. doi: 10.1155/2014/950903

98. Srivastava RM, Trivedi S, Concha-Benavente F, Hyun-Bae J, Wang L, Seethala RR, et al. STAT1-Induced HLA Class I Upregulation Enhances Immunogenicity and Clinical Response to Anti-EGFR mAb Cetuximab Therapy in HNC Patients. Cancer Immunol Res (2015) 3(8):936-45. doi: 10.1158/2326-6066.Cir-15-0053

99. Garrido G, Rabasa A, Garrido C, Chao L, Garrido F, García-Lora ÁM, et al. Upregulation of HLA Class I Expression on Tumor Cells by the Anti-EGFR Antibody Nimotuzumab. Front Pharmacol (2017) 8:595. doi: 10.3389/ fphar.2017.00595

100. Spiotto M, Fu Y-X, Weichselbaum RR. The intersection of radiotherapy and immunotherapy: mechanisms and clinical implications. Sci Immunol (2016) 1(3):EAAG1266. doi: 10.1126/sciimmunol.aag1266

101. Reits EA, Hodge JW, Herberts CA, Groothuis TA, Chakraborty M, Wansley EK, et al. Radiation modulates the peptide repertoire, enhances MHC class I expression, and induces successful antitumor immunotherapy. J Exp Med (2006) 203(5):1259-71. doi: 10.1084/jem.20052494

102. He YF, Zhang GM, Wang XH, Zhang H, Yuan Y, Li D, et al. [Eukaryotic expression and functional characterization of PD-1 extracellular domain]. Sheng Wu Gong Cheng Xue Bao (2004) 20(5):699-703.

103. He L, Zhang G, He Y, Zhu H, Zhang H, Feng Z. Blockade of B7-H1 with sPD-1 improves immunity against murine hepatocarcinoma. Anticancer Res (2005) 25(5):3309-13.
104. He YF, Zhang GM, Wang XH, Zhang H, Yuan Y, Li D, et al. Blocking programmed death-1 ligand-PD-1 interactions by local gene therapy results in enhancement of antitumor effect of secondary lymphoid tissue chemokine. J Immunol (2004) 173(8):4919-28. doi: 10.4049/ jimmunol.173.8.4919

105. Yuan Y, He Y, Wang X, Zhang H, Li D, Feng Z, et al. Investigation on the effects of soluble programmed death-1 (sPD-1) enhancing anti-tumor immune response. J Huazhong Univ Sci Technolog Med Sci (2004) 24 (6):531-4. doi: 10.1007/bf02911345

106. Amancha PK, Hong JJ, Rogers K, Ansari AA, Villinger F. In vivo blockade of the programmed cell death-1 pathway using soluble recombinant PD-1-Fc enhances CD4+ and CD8+ T cell responses but has limited clinical benefit. J Immunol (2013) 191(12):6060-70. doi: 10.4049/jimmunol.1302044

107. Elhag OA, Hu XJ, Wen-Ying Z, Li X, Yuan YZ, Deng LF, et al. Reconstructed adeno-associated virus with the extracellular domain of murine PD-1 induces antitumor immunity. Asian Pac J Cancer Prev APJCP (2012) 13 (8):4031-6. doi: 10.7314/apjcp.2012.13.8.4031

108. Dulos J, Carven GJ, van Boxtel SJ, Evers S, Driessen-Engels LJ, Hobo W, et al. PD-1 blockade augments Th1 and Th17 and suppresses Th2 responses in peripheral blood from patients with prostate and advanced melanoma cancer. J Immunother (Hagerstown Md 1997) (2012) 35(2):169-78. doi: 10.1097/CJI.0b013e318247a4e7

109. Liu C, Jiang J, Gao L, Wang X, Hu X, Wu M, et al. Soluble PD-1 aggravates progression of collagen-induced arthritis through Th1 and Th17 pathways. Arthritis Res Ther (2015) 17(1):340. doi: 10.1186/s13075-015-0859-Z

110. Wang X, Zhang Z, Zhang S, Fu J, Yao J, Jiao Y, et al. B7-H1 up-regulation impairs myeloid DC and correlates with disease progression in chronic HIV1 infection. Eur J Immunol (2008) 38(11):3226-36. doi: 10.1002/ eji. 200838285

111. Song MY, Park SH, Nam HJ, Choi DH, Sung YC. Enhancement of vaccineinduced primary and memory CD8(+) T-cell responses by soluble PD-1. J Immunother (Hagerstown Md 1997) (2011) 34(3):297-306. doi: 10.1097/ CJI.0b013e318210ed0e

112. Ruedl C, Kopf M, Bachmann MF. CD8(+) T cells mediate CD40independent maturation of dendritic cells in vivo. J Exp Med (1999) 189 (12):1875-84. doi: 10.1084/jem.189.12.1875

113. Min L, Mohammad Isa SA, Shuai W, Piang CB, Nih FW, Kotaka M, et al. Cutting edge: granulocyte-macrophage colony-stimulating factor is the major CD8+ T cell-derived licensing factor for dendritic cell activation. J Immunol (2010) 184(9):4625-9. doi: 10.4049/jimmunol.0903873

114. Butte MJ, Keir ME, Phamduy TB, Sharpe AH, Freeman GJ. Programmed death-1 ligand 1 interacts specifically with the B7-1 costimulatory molecule to inhibit T cell responses. Immunity (2007) 27(1):111-22. doi: 10.1016/ j.immuni.2007.05.016

115. Shin SP, Seo HH, Shin JH, Park HB, Lim DP, Eom HS, et al. Adenovirus expressing both thymidine kinase and soluble PD1 enhances antitumor immunity by strengthening CD8 T-cell response. Mol Ther (2013) 21 (3):688-95. doi: 10.1038/mt.2012.252

116. Qiu H, Liu S, Xie C, Long J, Feng Z. Regulating immunity and inhibiting tumor growth by the recombinant peptide SPD-1-CH50. Anticancer Res (2009) 29(12):5089-94.

117. Qiu H, Zhang H, Feng ZH, Geng H, Zhang GM. [Therapeutic effects of simultaneous expression of 4-1BBL and sPD-1 on experimental murine hepatoma]. Zhonghua Gan Zang Bing Za Zhi (2006) 14(7):505-9.

118. Xiao H, Huang B, Yuan Y, Li D, Han LF, Liu Y, et al. Soluble PD-1 facilitates 4-1BBL-triggered antitumor immunity against murine $\mathrm{H} 22$ hepatocarcinoma in vivo. Clin Cancer Res Off J Am Assoc Cancer Res (2007) 13(6):1823-30. doi: 10.1158/1078-0432.Ccr-06-2154

119. Geng H, Zhang GM, Xiao H, Yuan Y, Li D, Zhang H, et al. HSP70 vaccine in combination with gene therapy with plasmid DNA encoding sPD-1 overcomes immune resistance and suppresses the progression of pulmonary metastatic melanoma. Int J Cancer (2006) 118(11):2657-64. doi: $10.1002 / \mathrm{ijc} .21795$

120. Wang XH, Zhang GM, He YF, Zhang H, Feng ZH. [Soluble PD-1 can augment anti-tumor immunity induced by HSP70-peptide complex in tumor-bearing mice]. Xi Bao Yu Fen Zi Mian Yi Xue Za Zhi (2004) 20(6):655-8.

121. Pan XC, Li L, Mao JJ, Yao W, Zheng JN, Liu M, et al. Synergistic effects of soluble PD-1 and IL-21 on antitumor immunity against $\mathrm{H} 22$ murine 
hepatocellular carcinoma. Oncol Lett (2013) 5(1):90-6. doi: 10.3892/ ol.2012.966

122. Okuma Y, Wakui H, Utsumi H, Sagawa Y, Hosomi Y, Kuwano K, et al. Soluble Programmed Cell Death Ligand 1 as a Novel Biomarker for Nivolumab Therapy for Non-Small-cell Lung Cancer. Clin Lung Cancer (2018) 19(5):410-7.e1. doi: 10.1016/j.cllc.2018.04.014

123. Frigola X, Inman BA, Lohse CM, Krco CJ, Cheville JC, Thompson RH, et al. Identification of a soluble form of $\mathrm{B} 7-\mathrm{H} 1$ that retains immunosuppressive activity and is associated with aggressive renal cell carcinoma. Clin Cancer Res: Off J Am Assoc Cancer Res (2011) 17(7):1915-23. doi: 10.1158/10780432.CCR-10-0250

124. Jalali S, Price-Troska T, Paludo J, Villasboas J, Kim H-J, Yang Z-Z, et al. Soluble PD-1 ligands regulate T-cell function in Waldenstrom macroglobulinemia. Blood Adv (2018) 2(15):1985-97. doi: 10.1182/ bloodadvances.2018021113

125. Shigemori T, Toiyama Y, Okugawa Y, Yamamoto A, Yin C, Narumi A, et al. Soluble PD-L1 Expression in Circulation as a Predictive Marker for Recurrence and Prognosis in Gastric Cancer: Direct Comparison of the Clinical Burden Between Tissue and Serum PD-L1 Expression. Ann Surg Oncol (2019) 26(3):876-83. doi: 10.1245/s10434-018-07112-x

126. Okuma Y, Hosomi Y, Nakahara Y, Watanabe K, Sagawa Y, Homma S. High plasma levels of soluble programmed cell death ligand 1 are prognostic for reduced survival in advanced lung cancer. Lung Cancer (Amsterdam Netherlands) (2017) 104:1-6. doi: 10.1016/j.lungcan.2016.11.023

127. Gong B, Kiyotani K, Sakata S, Nagano S, Kumehara S, Baba S, et al. Secreted PD-L1 variants mediate resistance to PD-L1 blockade therapy in non-small cell lung cancer. J Exp Med (2019) 216(4):982. doi: 10.1084/jem.20180870

128. Bonomi M, Ahmed T, Addo S, Kooshki M, Palmieri D, Levine BJ, et al. Circulating immune biomarkers as predictors of the response to pembrolizumab and weekly low dose carboplatin and paclitaxel in NSCLC and poor PS: An interim analysis. Oncol Lett (2019) 17(1):1349-56. doi: $10.3892 /$ ol.2018.9724

129. Zhou J, Mahoney KM, Giobbie-Hurder A, Zhao F, Lee S, Liao X, et al. Soluble PD-L1 as a Biomarker in Malignant Melanoma Treated with Checkpoint Blockade. Cancer Immunol Res (2017) 5(6):480. doi: 10.1158/ 2326-6066.CIR-16-0329

130. Zhao J, Zhang P, Wang J, Xi Q, Zhao X, Ji M, et al. Plasma levels of soluble programmed death ligand-1 may be associated with overall survival in nonsmall cell lung cancer patients receiving thoracic radiotherapy. Medicine (2017) 96(7):e6102. doi: 10.1097/md.0000000000006102

131. Kim HJ, Park S, Kim K-J, Seong J. Clinical significance of soluble programmed cell death ligand-1 (sPD-L1) in hepatocellular carcinoma patients treated with radiotherapy. Radiother Oncol J Eur Soc Ther Radiol Oncol (2018) 129(1):130-5. doi: 10.1016/j.radonc.2017.11.027

132. Ha H, Nam AR, Bang JH, Park JE, Kim TY, Lee KH, et al. Soluble programmed death-ligand 1 (sPDL1) and neutrophil-to-lymphocyte ratio (NLR) predicts survival in advanced biliary tract cancer patients treated with palliative chemotherapy. Oncotarget (2016) 7(47):76604-12. doi: 10.18632/ oncotarget. 12810

133. Ha H, Bang J-H, Nam A-R, Park J-E, Jin MH, Bang Y-J, et al. Dynamics of Soluble Programmed Death-Ligand 1 (sPDL1) during Chemotherapy and Its Prognostic Implications in Cancer Patients: Biomarker Development in Immuno-oncology. Cancer Res Treat (2019) 51(2):832-40. doi: 10.4143/ crt.2018.311

134. Park W, Bang J-H, Nam A-R, Park JE, Kim MH, Oh KS, et al. Prognostic value of serum soluble programmed death-ligand 1 (sPDL1) and dynamics during chemotherapy in advanced gastric cancer patients. J Clin Oncol (2019) 37(15_suppl):4034-. doi: 10.1200/JCO.2019.37.15_suppl.4034

135. Armengol G, Ruiz LM, Orduz S. The injection of plasmid DNA in mouse muscle results in lifelong persistence of DNA, gene expression, and humoral response. Mol Biotechnol (2004) 27(2):109-18. doi: 10.1385/ $\mathrm{mb}: 27: 2: 109$

136. Faurez F, Dory D, Le Moigne V, Gravier R, Jestin A. Biosafety of DNA vaccines: New generation of DNA vectors and current knowledge on the fate of plasmids after injection. Vaccine (2010) 28(23):3888-95. doi: 10.1016/ j.vaccine.2010.03.040

137. Stone GW, Barzee S, Snarsky V, Kee K, Spina CA, Yu XF, et al. Multimeric soluble CD40 ligand and GITR ligand as adjuvants for human immunodeficiency virus DNA vaccines. J Virol (2006) 80(4):1762-72. doi: 10.1128 /jvi.80.4.1762-1772.2006

138. Muenst S, Läubli H, Soysal SD, Zippelius A, Tzankov A, Hoeller S. The immune system and cancer evasion strategies: therapeutic concepts. J Intern Med (2016) 279(6):541-62. doi: 10.1111/joim.12470

139. Lhuillier C, Rudqvist N-P, Elemento O, Formenti SC, Demaria S. Radiation therapy and anti-tumor immunity: exposing immunogenic mutations to the immune system. Genome Med (2019) 11(1):40-. doi: 10.1186/s13073-0190653-7

140. Khawli LA, Hu P, Epstein AL. Cytokine, chemokine, and co-stimulatory fusion proteins for the immunotherapy of solid tumors. Handb Exp Pharmacol (2008) (181):291-328. doi: 10.1007/978-3-540-73259-4_13

141. Wang JP, Hielscher A. Fibronectin: How Its Aberrant Expression in Tumors May Improve Therapeutic Targeting. J Cancer (2017) 8(4):674-82. doi: $10.7150 /$ jca. 16901

142. Gong W, Liu Y, Huang B, Lei Z, Wu FH, Li D, et al. Recombinant CBDHepII polypeptide of fibronectin inhibits alphavbeta3 signaling and hematogenous metastasis of tumor. Biochem Biophys Res Commun (2008) 367(1):144-9. doi: 10.1016/j.bbrc.2007.12.110

143. Liu Y, Huang B, Yuan Y, Gong W, Xiao H, Li D, et al. Inhibition of hepatocarcinoma and tumor metastasis to liver by gene therapy with recombinant CBD-HepII polypeptide of fibronectin. Int J Cancer (2007) 121(1):184-92. doi: 10.1002/ijc.22644

144. Abate-Daga D, Garcia-Rodríguez L, Sumoy L, Fillat C. Cell cycle control pathways act as conditioning factors for TK/GCV sensitivity in pancreatic cancer cells. Biochim Biophys Acta (2010) 1803(10):1175-85. doi: 10.1016/ j.bbamcr.2010.06.009

145. Chen SH, Shine HD, Goodman JC, Grossman RG, Woo SL. Gene therapy for brain tumors: regression of experimental gliomas by adenovirus-mediated gene transfer in vivo. Proc Natl Acad Sci United States America (1994) 91 (8):3054-7. doi: 10.1073/pnas.91.8.3054

146. Smythe WR, Hwang HC, Amin KM, Eck SL, Davidson BL, Wilson JM, et al. Use of recombinant adenovirus to transfer the herpes simplex virus thymidine kinase (HSVtk) gene to thoracic neoplasms: an effective in vitro drug sensitization system. Cancer Res (1994) 54(8):2055-9.

147. Tomicic MT, Thust R, Kaina B. Ganciclovir-induced apoptosis in HSV-1 thymidine kinase expressing cells: critical role of DNA breaks, Bcl-2 decline and caspase-9 activation. Oncogene (2002) 21(14):2141-53. doi: 10.1038/ sj.onc. 1205280

148. Assi H, Candolfi M, Baker G, Mineharu Y, Lowenstein PR, Castro MG. Gene therapy for brain tumors: basic developments and clinical implementation. Neurosci Lett (2012) 527(2):71-7. doi: 10.1016/j.neulet.2012.08.003

149. Rainov NG. A phase III clinical evaluation of herpes simplex virus type 1 thymidine kinase and ganciclovir gene therapy as an adjuvant to surgical resection and radiation in adults with previously untreated glioblastoma multiforme. Hum Gene Ther (2000) 11(17):2389-401. doi: 10.1089/ 104303400750038499

150. Rainov NG, Kramm CM, Banning U, Riemann D, Holzhausen HJ, Heidecke $\mathrm{V}$, et al. Immune response induced by retrovirus-mediated HSV-tk/GCV pharmacogene therapy in patients with glioblastoma multiforme. Gene Ther (2000) 7(21):1853-8. doi: 10.1038/sj.gt.3301311

151. King GD, Kroeger KM, Bresee CJ, Candolfi M, Liu C, Manalo CM, et al. Flt3L in combination with HSV1-TK-mediated gene therapy reverses brain tumor-induced behavioral deficits. Mol Ther (2008) 16(4):682-90. doi: $10.1038 / \mathrm{mt} .2008 .18$

152. Brockstedt DG, Diagana M, Zhang Y, Tran K, Belmar N, Meier M, et al. Development of anti-tumor immunity against a non-immunogenic mammary carcinoma through in vivo somatic GM-CSF, IL-2, and HSVtk combination gene therapy. Mol Ther (2002) 6(5):627-36. doi: 10.1006/mthe.2002.0722

153. Hollingsworth RE, Jansen K. Turning the corner on therapeutic cancer vaccines. NPJ Vac (2019) 4(1):7. doi: 10.1038/s41541-019-0103-y

154. Varn FS, Schaafsma E, Wang Y, Cheng C. Genomic characterization of six virus- associated cancers identifies changes in the tumor immune microenvironment and altered genetic programs. Cancer Res (2018) 78:6413-23. doi: 10.1158/0008-5472.CAN-18-1342

155. Sasagawa $T$, Inoue $M$, Inoue $H$, Yutsudo $M$, Tanizawa $O$, Hakura A. Induction of uterine cervical neoplasias in mice by human papillomavirus type 16 E6/E7 genes. Cancer Res (1992) 52(16):4420-6. 
156. Ramos CA, Narala N, Vyas GM, Leen AM, Gerdemann U, Sturgis EM, et al. Human papillomavirus type 16 E6/E7-specific cytotoxic T lymphocytes for adoptive immunotherapy of HPV-associated malignancies. I Immunother (Hagerstown Md 1997) (2013) 36(1):66-76. doi: 10.1097/CJI.0b013e 318279652e

157. Yang A, Farmer E, Wu TC, Hung C-F. Perspectives for therapeutic HPV vaccine development. J Biomed Sci (2016) 23(1):75. doi: 10.1186/s12929-0160293-9

158. zur Hausen H. Papillomaviruses in the causation of human cancers - a brief historical account. Virology (2009) 384(2):260-5. doi: 10.1016/ j.virol.2008.11.046

159. Shibata T, Lieblong BJ, Sasagawa T, Nakagawa M. The promise of combining cancer vaccine and checkpoint blockade for treating HPV-related cancer. Cancer Treat Rev (2019) 78:8-16. doi: 10.1016/j.ctrv.2019.07.001

160. Yang W, Song Y, Lu YL, Sun JZ, Wang HW. Increased expression of programmed death (PD)-1 and its ligand PD-L1 correlates with impaired cell-mediated immunity in high-risk human papillomavirus-related cervical intraepithelial neoplasia. Immunology (2013) 139(4):513-22. doi: 10.1111/ imm.12101

161. Rice AE, Latchman YE, Balint JP, Lee JH, Gabitzsch ES, Jones FR. An HPVE6/E7 immunotherapy plus PD-1 checkpoint inhibition results in tumor regression and reduction in PD-L1 expression. Cancer Gene Ther (2015) 22 (9):454-62. doi: 10.1038/cgt.2015.40

162. Liu Z, Zhou H, Wang W, Fu YX, Zhu M. A novel dendritic cell targeting HPV16 E7 synthetic vaccine in combination with PD-L1 blockade elicits therapeutic antitumor immunity in mice. Oncoimmunology (2016) 5(6): e1147641. doi: 10.1080/2162402x.2016.1147641

163. Lin PL, Cheng YM, Wu DW, Huang YJ, Lin HC, Chen CY, et al. A combination of anti-PD-L1 mAb plus Lm-LLO-E6 vaccine efficiently suppresses tumor growth and metastasis in HPV-infected cancers. Cancer Med (2017) 6(9):2052-62. doi: 10.1002/cam4.1143

164. Dorta-Estremera S, Chin RL, Sierra G, Nicholas C, Yanamandra AV, Nookala SMK, et al. Mucosal HPV E6/E7 Peptide Vaccination in Combination with Immune Checkpoint Modulation Induces Regression of HPV(+) Oral Cancers. Cancer Res (2018) 78(18):5327-39. doi: 10.1158/ 0008-5472.Can-18-0892

165. Chandra J, Dutton JL, Li B, Woo WP, Xu Y, Tolley LK, et al. DNA Vaccine Encoding HPV16 Oncogenes E6 and E7 Induces Potent Cell-mediated and Humoral Immunity Which Protects in Tumor Challenge and Drives E7expressing Skin Graft Rejection. J Immunother (Hagerstown Md 1997) (2017) 40(2):62-70. doi: 10.1097/cji.0000000000000156

166. van Zyl DG, Mautner J, Delecluse H-J. Progress in EBV Vaccines. Front Oncol (2019) 9:104. doi: 10.3389/fonc.2019.00104

167. Stankiewicz AR, Lachapelle G, Foo CP, Radicioni SM, Mosser DD. Hsp70 inhibits heat-induced apoptosis upstream of mitochondria by preventing Bax translocation. J Biol Chem (2005) 280(46):38729-39. doi: 10.1074/ jbc.M509497200

168. Schmitt E, Parcellier A, Gurbuxani S, Cande C, Hammann A, Morales MC, et al. Chemosensitization by a Non-apoptogenic Heat Shock Protein 70Binding Apoptosis-Inducing Factor Mutant. Cancer Res (2003) 63(23):8233.

169. Zong J, Wang C, Liu B, Liu M, Cao Y, Sun X, et al. Human hsp70 and HPV16 oE7 fusion protein vaccine induces an effective antitumor efficacy. Oncol Rep (2013) 30(1):407-12. doi: 10.3892/or.2013.2445

170. Crane CA, Han SJ, Ahn B, Oehlke J, Kivett V, Fedoroff A, et al. Individual Patient-Specific Immunity against High-Grade Glioma after Vaccination with Autologous Tumor Derived Peptides Bound to the 96 KD Chaperone Protein. Clin Cancer Res (2013) 19(1):205. doi: 10.1158/1078-0432.CCR-11-3358

171. Caudill MM, Li Z. HSPPC-96: a personalised cancer vaccine. Expert Opin Biol Ther (2001) 1(3):539-47. doi: 10.1517/14712598.1.3.539

172. Gong J, Zhang Y, Durfee J, Weng D, Liu C, Koido S, et al. A Heat Shock Protein 70-Based Vaccine with Enhanced Immunogenicity for Clinical Use. J Immunol (2010) 184(1):488. doi: 10.4049/jimmunol.0902255

173. Blachere NE, Li Z, Chandawarkar RY, Suto R, Jaikaria NS, Basu S, et al. Heat shock protein-peptide complexes, reconstituted in vitro, elicit peptidespecific cytotoxic T lymphocyte response and tumor immunity. J Exp Med (1997) 186(8):1315-22. doi: 10.1084/jem.186.8.1315

174. Binder RJ, Blachere NE, Srivastava PK. Heat shock protein-chaperoned peptides but not free peptides introduced into the cytosol are presented efficiently by major histocompatibility complex I molecules. J Biol Chem (2001) 276(20):17163-71. doi: 10.1074/jbc.M011547200

175. Schmid TE, Multhoff G. Radiation-induced stress proteins - the role of heat shock proteins (HSP) in anti- tumor responses. Curr Med Chem (2012) 19 (12):1765-70. doi: 10.2174/092986712800099767

176. Etminan N, Peters C, Lakbir D, Bünemann E, Börger V, Sabel MC, et al. Heat-shock protein 70-dependent dendritic cell activation by 5aminolevulinic acid-mediated photodynamic treatment of human glioblastoma spheroids in vitro. Br J Cancer (2011) 105(7):961-9. doi: 10.1038/bjc.2011.327

177. Xie Y, Bai O, Zhang H, Yuan J, Zong S, Chibbar R, et al. Membrane-bound HSP70-engineered myeloma cell-derived exosomes stimulate more efficient CD8(+) CTL- and NK-mediated antitumour immunity than exosomes released from heat-shocked tumour cells expressing cytoplasmic HSP70. J Cell Mol Med (2010) 14(11):2655-66. doi: 10.1111/j.15824934.2009.00851.x

178. Wang XP, Wang QX, Lin HP, Xu B, Zhao Q, Chen K. Recombinant heat shock protein 70 functional peptide and alpha-fetoprotein epitope peptide vaccine elicits specific anti-tumor immunity. Oncotarget (2016) 7(44):7127484. doi: 10.18632/oncotarget.12464

179. Dodd K, Nance S, Quezada M, Janke L, Morrison JB, Williams RT, et al. Tumor-derived inducible heat-shock protein 70 (HSP70) is an essential component of anti-tumor immunity. Oncogene (2015) 34(10):1312-22. doi: 10.1038/onc.2014.63

180. Enomoto Y, Bharti A, Khaleque AA, Song B, Liu C, Apostolopoulos V, et al. Enhanced immunogenicity of heat shock protein 70 peptide complexes from dendritic cell-tumor fusion cells. J Immunol (Baltimore Md 1950) (2006) 177 (9):5946-55. doi: 10.4049/jimmunol.177.9.5946

181. Mbofung RM, McKenzie JA, Malu S, Zhang M, Peng W, Liu C, et al. HSP90 inhibition enhances cancer immunotherapy by upregulating interferon response genes. Nat Commun (2017) 8(1):451. doi: 10.1038/s41467-01700449-z

182. Proia DA, Kaufmann GF. Targeting Heat-Shock Protein 90 (HSP90) as a Complementary Strategy to Immune Checkpoint Blockade for Cancer Therapy. Cancer Immunol Res (2015) 3(6):583-9. doi: 10.1158/23266066.Cir-15-0057

183. Kryeziu K, Bruun J, Guren TK, Sveen A, Lothe RA. Combination therapies with HSP90 inhibitors against colorectal cancer. Biochim Biophys Acta (BBA) - Rev Cancer (2019) 1871(2):240-7. doi: 10.1016/j.bbcan.2019.01.002

184. Chen Z, Hu K, Feng L, Su R, Lai N, Yang Z, et al. Senescent cells reengineered to express soluble programmed death receptor-1 for inhibiting programmed death receptor-1/programmed death ligand-1 as a vaccination approach against breast cancer. Cancer Sci (2018) 109(6):1753-63. doi: $10.1111 /$ cas. 13618

185. Ong SM, Hadadi E, Dang TM, Yeap WH, Tan CT, Ng TP, et al. The proinflammatory phenotype of the human non-classical monocyte subset is attributed to senescence. Cell Death Dis (2018) 9(3):266. doi: 10.1038/ s41419-018-0327-1

186. Onlamoon N, Rogers K, Mayne AE, Pattanapanyasat K, Mori K, Villinger F, et al. Soluble PD-1 rescues the proliferative response of simian immunodeficiency virus-specific CD4 and CD8 T cells during chronic infection. Immunology (2008) 124(2):277-93. doi: 10.1111/j.1365-2567.2007.02766.x

187. Conlon KC, Miljkovic MD, Waldmann TA. Cytokines in the Treatment of Cancer. J Interferon Cytokine Res (2019) 39(1):6-21. doi: 10.1089/ jir.2018.0019

188. Ju X, Zhang H, Zhou Z, Wang Q. Regulation of PD-L1 expression in cancer and clinical implications in immunotherapy. Am J Cancer Res (2020) 10 (1):1-11.

189. Shen X, Zhang L, Li J, Li Y, Wang Y, Xu Z-X. Recent Findings in the Regulation of Programmed Death Ligand 1 Expression. Front Immunol (2019) 10:1337. doi: 10.3389/fimmu.2019.01337

190. Enwere EK, Kornaga EN, Dean M, Koulis TA, Phan T, Kalantarian M, et al. Expression of PD-L1 and presence of CD8-positive T cells in pre-treatment specimens of locally advanced cervical cancer. Mod Pathol (2017) 30(4):57786. doi: 10.1038/modpathol.2016.221

191. Chen A-H, Qin Y-E, Tang W-F, Tao J, Song H-m, Zuo M. MiR-34a and miR-206 act as novel prognostic and therapy biomarkers in cervical cancer. Cancer Cell Int (2017) 17(1):63. doi: 10.1186/s12935-017-0431-9 
192. Qin Y-E, Tang W-F, Xu Y, Wan F-R, Chen A-H. Ultrasound-Mediated CoDelivery of miR-34a and sPD-1 Complexed with Microbubbles for Synergistic Cancer Therapy. Cancer Manag Res (2020) 12:2459-69. doi: 10.2147/CMAR.S238643

193. Kim TK, Herbst RS, Chen L. Defining and Understanding Adaptive Resistance in Cancer Immunotherapy. Trends Immunol (2018) 39(8):62431. doi: 10.1016/j.it.2018.05.001

194. Hargadon KM, Johnson CE, Williams CJ. Immune checkpoint blockade therapy for cancer: An overview of FDA-approved immune checkpoint inhibitors. Int Immunopharmacol (2018) 62:29-39. doi: 10.1016/j.intimp.2018.06.001

195. Ghahremanloo A, Soltani A, Modaresi SMS, Hashemy SI. Recent advances in the clinical development of immune checkpoint blockade therapy. Cell Oncol (Dordr) (2019) 42(5):609-26. doi: 10.1007/s13402-019-00456-w

196. Khair DO, Bax HJ, Mele S, Crescioli S, Pellizzari G, Khiabany A, et al. Combining Immune Checkpoint Inhibitors: Established and Emerging Targets and Strategies to Improve Outcomes in Melanoma. Front Immunol (2019) 10:453. doi: 10.3389/fimmu.2019.00453

197. Wolchok JD, Chiarion-Sileni V, Gonzalez R, Rutkowski P, Grob JJ, Cowey CL, et al. Overall Survival with Combined Nivolumab and Ipilimumab in Advanced Melanoma. N Engl J Med (2017) 377(14):1345-56. doi: 10.1056/ NEJMoa1709684

198. Motzer RJ, Tannir NM, McDermott DF, Arén Frontera O, Melichar B, Choueiri TK, et al. Nivolumab plus Ipilimumab versus Sunitinib in Advanced Renal-Cell Carcinoma. N Engl J Med (2018) 378(14):1277-90. doi: 10.1056/NEJMoa1712126

199. Hellmann MD, Rizvi NA, Goldman JW, Gettinger SN, Borghaei H, Brahmer JR, et al. Nivolumab plus ipilimumab as first-line treatment for advanced non-smallcell lung cancer (CheckMate 012): results of an open-label, phase 1, multicohort study. Lancet Oncol (2017) 18(1):31-41. doi: 10.1016/s1470-2045(16)30624-6

200. Antonia SJ, López-Martin JA, Bendell J, Ott PA, Taylor M, Eder JP, et al. Nivolumab alone and nivolumab plus ipilimumab in recurrent small-cell lung cancer (CheckMate 032): a multicentre, open-label, phase 1/2 trial. Lancet Oncol (2016) 17(7):883-95. doi: 10.1016/s1470-2045(16)30098-5

201. Qin S, Xu L, Yi M, Yu S, Wu K, Luo S. Novel immune checkpoint targets: moving beyond PD-1 and CTLA-4. Mol Cancer (2019) 18(1):155. doi: 10.1186/s12943-019-1091-2

202. Marin-Acevedo JA, Dholaria B, Soyano AE, Knutson KL, Chumsri S, Lou Y. Next generation of immune checkpoint therapy in cancer: new developments and challenges. J Hematol Oncol (2018) 11(1):39. doi: 10.1186/s13045-018-0582-8

203. Yang Z-Z. Expression and function of tigit in B-cell non-hodgkin lymphoma. Blood (2016) 128:4138. doi: 10.1182/blood.V128.22.4138.4138

204. Jin HT, Anderson AC, Tan WG, West EE, Ha SJ, Araki K, et al. Cooperation of TIM-3 and PD-1 in CD8 T-cell exhaustion during chronic viral infection. Proc Natl Acad Sci USA (2010) 107:14733-8. doi: 10.1073/pnas.1009731107

205. Zhou Q, Munger ME, Veenstra RG, Weigel BJ, Hirashima M, Munn DH, et al. Coexpression of TIM-3 and PD-1 identifies a CD8+ T-cell exhaustion phenotype in mice with disseminated acute myelogenous leukemia. Blood (2011) 117:4501-10. doi: 10.1182/blood-2010-10-310425

206. Fourcade J, Sun Z, Benallaoua M, Guillaume P, Luescher IF, Sander C, et al. Upregulation of TIM-3 and PD-1 expression is associated with tumor antigen-specific CD8+ T cell dysfunction in melanoma patients. J Exp Med (2010) 207:2175-86. doi: 10.1084/jem.20100637

207. Linedale R, Schmidt C, King BT, Ganko AG, Simpson F, Panizza BJ, et al. Elevated frequencies of CD8T cells expressing PD-1, CTLA-4 and TIM-3 within tumour from perineural squamous cell carcinoma patients. PloS One (2017) 12:e0175755. doi: 10.1371/journal.pone.0175755
208. Liu F, Zeng G, Zhou S, He X, Sun N, Zhu X, et al. Blocking TIM- 3 or/and $\mathrm{PD}-1$ reverses dysfunction of tumor-infiltrating lymphocytes in HBV-related hepatocellular carcinoma. Bull Cancer (2018) 105:493-501. doi: 10.1016/ j.bulcan.2018.01.018

209. Shen H, Sheng H, Lu JJ, Feng C, Yao M, Pan H, et al. Expression and distribution of programmed death receptor 1 and $\mathrm{T}$ cell immunoglobulin mucin 3 in breast cancer microenvironment and its relationship with clinicopathological features. Zhonghua Yi Xue Za Zhi (2018) 98:1352-7. doi: 10.3760/cma.j.issn.0376-2491.2018.17.014

210. Khan M, Arooj S, Wang H. NK Cell-Based Immune Checkpoint Inhibition. Front Immunol (2020) 11:167. doi: 10.3389/fimmu.2020.00167

211. Khan M, Lin J, Liao G, Tian Y, Liang Y, Li R, et al. SRS in Combination With Ipilimumab: A Promising New Dimension for Treating Melanoma Brain Metastases. Technol Cancer Res Treat (2018) 17:1533033818798792. doi: 10.1177/1533033818798792

212. Liniker E, Menzies AM, Kong BY, Cooper A, Ramanujam S, Lo S, et al. Activity and safety of radiotherapy with anti-PD-1 drug therapy in patients with metastatic melanoma. Oncoimmunology (2016) 5(9):e1214788. doi: 10.1080/2162402x.2016.1214788

213. Zitvogel L, Galluzzi L, Smyth MJ, Kroemer G. Mechanism of action of conventional and targeted anticancer therapies: reinstating immunosurveillance. Immunity (2013) 39(1):74-88. doi: 10.1016/j.immuni.2013.06.014

214. Roselli M, Cereda V, di Bari MG, Formica V, Spila A, Jochems C, et al. Effects of conventional therapeutic interventions on the number and function of regulatory T cells. Oncoimmunology (2013) 2(10):e27025-e. doi: 10.4161/ onci. 27025

215. Wang Z, Till B, Gao Q. Chemotherapeutic agent-mediated elimination of myeloid-derived suppressor cells. Oncoimmunology (2017) 6(7):e1331807. doi: 10.1080/2162402x.2017.1331807

216. Galluzzi L, Buqué A, Kepp O, Zitvogel L, Kroemer G. Immunological Effects of Conventional Chemotherapy and Targeted Anticancer Agents. Cancer Cell (2015) 28(6):690-714. doi: 10.1016/j.ccell.2015.10.012

217. Bracci L, Schiavoni G, Sistigu A, Belardelli F. Immune-based mechanisms of cytotoxic chemotherapy: implications for the design of novel and rationalebased combined treatments against cancer. Cell Death Differ (2014) 21 (1):15-25. doi: 10.1038/cdd.2013.67

218. Peng J, Hamanishi J, Matsumura N, Abiko K, Murat K, Baba T, et al. Chemotherapy Induces Programmed Cell Death-Ligand 1 Overexpression via the Nuclear Factor- $\kappa \mathrm{B}$ to Foster an Immunosuppressive Tumor Microenvironment in Ovarian Cancer. Cancer Res (2015) 75(23):5034-45. doi: 10.1158/0008-5472.Can-14-3098

219. Weinberg F, Gadgeel S. Combination pembrolizumab plus chemotherapy: a new standard of care for patients with advanced non-small-cell lung cancer. Lung Cancer (Auckl) (2019) 10:47-56. doi: 10.2147/LCTT.S176391

Conflict of Interest: The authors declare that the research was conducted in the absence of any commercial or financial relationships that could be construed as a potential conflict of interest.

Copyright (๑) 2020 Khan, Zhao, Arooj, Fu and Liao. This is an open-access article distributed under the terms of the Creative Commons Attribution License (CC BY). The use, distribution or reproduction in other forums is permitted, provided the original author(s) and the copyright owner(s) are credited and that the original publication in this journal is cited, in accordance with accepted academic practice. No use, distribution or reproduction is permitted which does not comply with these terms. 